\title{
Aligning Perspectives and Methods for Value-Driven Design
}

\author{
Adam M. Ross ${ }^{*}$, M. Gregory O’Neill ${ }^{\dagger}$, Daniel E. Hastings ${ }^{\ddagger}$, Donna H. Rhodes ${ }^{\S}$ \\ Massachusetts Institute of Technology, Cambridge, MA, 02139
}

\begin{abstract}
Recent years have seen a push to use explicit consideration of "value" in order to drive design. This paper conveys the need to explicitly align perspectives on "value" with the method used to quantify "value." Various concepts of value are introduced in the context of its evolution within economics in order to propose a holistic definition of value. Operationalization of value is discussed, including possible assumption violations in the aerospace domain. A series of prominent Value-Centric Design Methodologies for valuation are introduced, including Net Present Value, Multi-Attribute Utility Theory, and CostBenefit Analysis. These methods are compared in terms of the assumptions they make with regard to operationalizing value. It is shown that no method is fully complete in capturing the definition of value, but selecting the most appropriate one involves matching the particular system application being valued with acceptable assumptions for valuation. Two case studies, a telecommunications mission and a deep-space observation mission, are used to illustrate application of the three prior mentioned valuation methods. The results of the studies show that depending on method used for valuation, very different conclusions and insights will be derived, therefore an explicit consideration of the appropriate definition of value is necessary in order to align a chosen method with desired valuation insights.
\end{abstract}

\section{Introduction}

$\mathrm{I}_{\mathrm{i}+\mathrm{n}}^{\mathrm{n}}$ recent years, the desire to use the concept of "value" to drive the design of complex engineering systems has increased appreciably. This trend is directly evident in government spacecraft acquisition programs such as the Defense Advanced Research Projects Agency System F6 program. ${ }^{1,2,3,4,5,6,7,8,9,10,11,12,13}$ Similarly, this trend has been observed in academic research. ${ }^{1-13}$ In industry, government, and academia, value-driven design is often portrayed as a response to more traditional (and historical) approaches for designing engineering systems, which rely heavily on requirements and/or cost-related characteristics of a system. Subsequently, these traditional approaches for engineering design, although originally intended to lead to the creation of useful systems, often end up falling short in delivering to their full potential, either by costing too much, or providing less capability than expected. Turning to "value" as a driver seeks to mitigate these shortcomings by focusing system design and evaluation using both costs and benefits in a more intentional and integrated manner.

The result of this recent desire to pursue value-driven design has been the creation of what are commonly referred to as "value-centric design methodologies" $(\mathrm{VCDMs})^{4}$; these subsequently embody the synergy between value-driven design and engineering system design. Essentially, these VCDMs marry physics and cost-based system models with a valuation model, the latter incorporating value perception as part of the system model output, and thus providing system selection criteria based on derived system value. In the aforementioned System F6 Program as well as the recent literature, these VCDMs have been suggested as providing unique insight for the selection of the most "valuable" system design from amongst a set of candidate system designs. Subsequently, this makes VCDMs particularly applicable during the early stages of a system design, such as during the concept generation and evaluation phase. ${ }^{14}$

This paper seeks to assess the current state of value-driven design in the context of aerospace system design. The resulting contributions of, and thus motivation for, this paper are four-fold. First, the paper provides a contextual introduction and discussion on the evolution of the nuanced meaning of "value" with the intent of addressing how one can "value" a system (e.g., a "good" in economics terminology). Identifying the perceiver of

\footnotetext{
${ }^{*}$ Research Scientist, Engineering Systems Division, Bldg. E38-574, and AIAA Senior Member.

${ }^{\dagger}$ Graduate Research Assistant, Aeronautics and Astronautics, Bldg. E38-550, and AIAA Student Member.

* Professor of Aeronautics and Astronautics and Engineering Systems Division, Dean for Undergraduate Education, Bldg. 4-110, and AIAA Fellow.

$\S$ Principal Research Scientist, Engineering Systems Division, Bldg. E38-572, and AIAA Member.
} 
"value" is essential for pursuing value-driven design. The second part of this paper extends the previous discussion of the concept of value into a discussion about the economics of value. Specifically, this discussion introduces various "schools of thought" surrounding the meaning of value, as well as the implications of its interpretation in accepted economic theory. Each interpretation is presented in order to make explicit the differences that underlie economic methods that are used to quantify value, which can aid an analyst in structuring their perception of value and subsequently verify that their value perception conforms to a particular economic theory. Additionally, this second section is intended to illustrate the infancy of value-driven design in the context of engineering system design. Applying economic methods to engineering design implicitly assumes the applicability of such methods. A brief discussion introduces behavioral economics, a dual-discipline area of study merging psychology and economics, which can be an alternative source of methods for engineering design. Any cross-field application of methods requires caution, as underlying assumptions, previously uncontroversial, may become critical barriers to successful implementation. This issue becomes particularly relevant when "pushing" value-driven design beyond what is currently accepted and understood in psychology and economics, with regard to valuing systems.

After introducing alternative interpretations and sources for value, the third part of this paper discusses the operationalization of the value evaluation aspect of value-driven design, in the context of the aerospace domain. To provide scope to this work, this operationalization assumes that system value is derived, and thus perceived, by system stakeholders. In particular, seven prominent valuation methods typically used in VCDMs are introduced and discussed: Net Present Value (NPV), Multi-Attribute Utility Theory (MAUT), Cost-Benefit Analysis (CBA), Cumulative Prospect Theory (CPT), Value Functions (VFs), Analytic Hierarchy Process (AHP), and Technique for Order Preference by Similarity to Ideal Solution (TOPSIS). ${ }^{7,15,16,17,18,19,20,21,22,23,57,58}$ The emphasis in the discussion of these VCDMs is to provide a comprehensive information base for the more popular approaches (i.e., VCDMs) for operationalizing value-driven design in the context of engineering system design - provided that the value generated by a system is assumed to be perceived by the stakeholder(s) of that system. The discussion of these VCDMs also explicitly states the definition of value, as quantified by each VCDM, and emphasizes the inherent assumptions in these VCDMs, thereby illustrating the need for a VCDM-user to be comfortable with making these assumptions and accepting the resulting credibility of the VCDM outputs.

The fourth part of the paper demonstrates the applicability and capability of three widely used VCDMs -- NPV, MAUT, and CBA -- for the valuation of systems. Specifically, this is done through a working example in which monolithic spacecraft, performing either a telecommunications or deep-space observation mission, are modeled and then valued via each of these three VCDMs. For each of these missions, a pseudo stakeholder is used and their respective preference structure is used to derive a value proposition and attributes for the mission.

A spacecraft modeling tool called the Spacecraft Evaluation Tool (SET) performs the quantitative physics and cost-based modeling as well as execution of NPV, MAUT, and CBA for the valuation of more than 190 alternative designs of these monolithic spacecraft. ${ }^{24}$ Under the assumption that value perception is derived from stakeholders, this fourth part provides a direct comparison between the valuations of spacecraft using each of these three VCDMs. This part of the paper provides a concrete example to wrap-up the discussion found in this paper regarding the pursuit of value-driven design in the context of engineering aerospace systems.

\section{The Concept of Value}

The idea of creating "value" is a well-accepted goal for project endeavors. Business leaders have long espoused creating "shareholder value," economists use it as a basic concept underlying markets, and consultants use it to justify their specialized interventions. From an engineering perspective, the concept of creating value goes hand-inhand with fundamental goals in system and product design (meeting customer or user needs), as well as systems engineering (capturing requirements and developing systems that meet them). However, part of the lack of controversy is due to the inherent ambiguity of the term "value." It inherently speaks of creating "goodness," but in order to use the concept as a motivator, assessor, and quantitative evaluator of the goodness of engineering system alternatives, the term must be unambiguously understood, including subtle nuances in how the term has been used in other domains and the assumptions necessary for its quantification.

\section{A. Multiplicity of Definitions of Value}

The definition of value itself may be a source of confusion, or at the very least, miscommunication about the underlying concept being discussed. Part of this confusion stems from the imprecision by which the term is defined, both colloquially (within conversational use), as well as technically (within professional use). Some have even gone so far as to denounce the usage of the term since much of its ambiguity arises from its application to encompass 
multiple distinct meanings related to such concepts as satisfaction, morality, and truth ${ }^{25}$. As a more modern example, consider the first three definitions of "value" as listed in Miriam-Webster Online dictionary ${ }^{26}$ :

$1:$ a fair return or equivalent in goods, services, or money for something exchanged

$2:$ the monetary worth of something : market price

3 : relative worth, utility, or importance <a good value at the price $><$ the value of base stealing in baseball $><$ had nothing of value to say>

The first definition, explicitly equates "value" with its equivalence in exchange, where the equivalent medium of exchange could be defined as "goods, services, or money." The second definition focuses on the medium of exchange as monetary, and represents the common usage of the term in financial contexts. The third definition speaks of "relative worth, utility, or importance" suggesting that value is not just about a concrete representation of equivalence, but rather a balance of benefit at cost (worth), satisfaction or usefulness (utility), and priority (importance). This definition is much broader than the first two and aligns more closely with "value" as used in decision contexts, where value is created in finding solutions that solve problems which may or may not involve monetary exchanges. Since the context of "design" involves more than just monetary exchange, especially when the desired capabilities of the ultimate system being created may be cast in terms difficult to monetize, the broader, third definition is most appropriate for "value-driven design."

Given the third, multifaceted definition of "value," the notion of "creating value" likewise becomes multifaceted. In order to create value, one must advance the current level of "value," expressed as some combination of "worth, utility, and/or importance" above some prior level. Net worth, in economic terms, is often cast as the total amount of money for which an individual, good, or service can be exchanged. A slightly weaker interpretation is the amount of money an individual has at his disposal. An individual's "wealth level" is sometimes equated with the amount of resources that an individual could bring to an exchange. Implicit in the concept of wealth level is the bundle of goods and services that could be acquired for a given level of wealth, the higher the level of wealth, the larger the bundle of goods and services that could be acquired. Therefore, an individual often seeks to maximize wealth and/or minimize its expenditure. Utility is the ultimate satisfaction level of the individual engaged in the exchange. It is typically assumed that rational individuals seek utility-increasing exchanges. Lastly, the importance level relates to the internal priorities that an individual sets and relates to internal principles used for ranking alternative courses of action. Taken together, these three facets of value-resources, satisfaction, and prioritiescan be used to develop a more holistic definition of value creation. Value creation can be considered as lowering the level of needed resources, raising the level of satisfaction, meeting higher priorities, or some combination thereof, relative to some baseline situation. At this point, one may notice an inherent subjective quality to the holistic definition of value. That is, while resources could be objectively measured, satisfaction and priorities are clearly in the "mind of the beholder." Pragmatically, satisfaction is determined by meeting or exceeding important expectations, which may vary across individuals, organizations, and contexts.

\section{Holistic definition of creating value:}

Balancing and increasing the net level of (1) satisfaction, with (2) available resources, while addressing (3) its degree of importance

\section{B. Creating Value in Design}

Many authors address the topic of value creation, often a fundamental goal for design, in different ways. For example, depending on the originating domain, various assumptions are made on the expectations of the "perceiver of value." For financial domains, especially for profit-driven ventures, the ultimate "value" is the creation of wealth, where satisfaction is derived by having more money, resources are typically considered in terms of money, and priorities are focused on whether the money is available today or tomorrow. The "value" of alternative options in these types of problems degenerates into a time and money assessment of the alternatives.

For more general problems, value is inherently more complex, where satisfaction is not derived from money alone, and where resources are more generally accounted for as "currency exchanges" of scarce resources such as money, energy, information, matter, and perhaps time and labor as well. In this more general case, satisfaction is derived from multiple sources and may be entirely context-dependent, that is, satisfaction is only well-defined within a particular frame of use and manner that sets expectations for what is deemed a "useful" outcome. In such contexts, the "perceiver" must interpret the outcomes relative to what is expected and interpreted as "good" on this scale. For example, after a cold, wintery month, the "heated seats" feature in a car is perceived as a satisfaction 
increasing feature and adds "value" to one's car. That same car, perceived by the same owner, may not see that feature as "value-adding" after moving to a warm weather climate.

Given that "value" is subjectively determined by individuals, how can "value" be assessed in order to drive design?" Many approaches have been taken in order to use "value" as a motivator for design. These approaches must choose whether to maximize the value perceived by each individual, or across many individuals, thereby inherently making assumptions about the tradeoff of creating value differentially across individuals. If one assumes the goal is to create the greatest good for the greatest number, then one is following Utilitarianism principles ${ }^{27}$, and this is a choice, often implicitly made. In order to aggregate across individuals, however, one must assume the relative importance of each individual. Egalitarianism maintains that all individuals should be treated equally. Egalitarian utilitarian principles are often implicitly assumed in engineering design methods that attempt to aggregate across individuals without respect to their personal and distinct perception of value, as well as the assumption that that aggregate should be maximized".

\title{
C. Schools of Thought
}

Defining value precisely is not a new dilemma and in fact dates back to earlier days of economic thought:

\begin{abstract}
The word value, it is to be observed, has two different meanings, and sometimes expresses the utility of some particular object, and sometimes the power of purchasing other goods which the possession of that object conveys. The one may be called "value in use"; the other, "value in exchange." The things which have the greatest value in use have frequently little or no value in exchange; and, on the contrary, those which have the greatest value in exchange have frequently little or no value in use. Nothing is more useful than water: but it will purchase scarce anything; scarce anything can be had in exchange for it. A diamond, on the contrary, has scarce any value in use; but a very great quantity of other goods may frequently be had in exchange for it. $^{28}$
\end{abstract}

This seminal work in early economics was soon replaced by David Ricardo's Principles of Political Economy and Taxation, published in 1817. In this work, Ricardo confronts the "diamond-water paradox" of Smith as one that misses a fundamental connection between "value in use" and "value in exchange": that "use value is essential for the existence of exchange value, though not its measure" ${ }^{29}$ In other words, for something to have "value in exchange" (i.e., a "price"), a demand must exist for it, but the level of demand itself is not a measure of price. According to Ricardo, prices for goods are determined by two sources: scarcity and labor required to produce them, however some items (i.e., "non-commodities") have prices determined by scarcity alone. Finding Ricardo's (supply-side) theory of value lacking in generality and ability to predict prices, three economists in the 1870s (Jevons, Menger, and Walras) each independently proposed an alternative demand-side theory in which value is determined during consumption through its utility, in particular through its marginal utility to a consumer, and not through its past (i.e., independent of how a good is made, its price is set based on how people derive utility from it in "use"). ${ }^{30}$ However, focusing solely on the demand-side proved insufficient to explain how firms set prices when supplies are not fixed, and the definition of value then shifted back to including supply-side considerations, using both marginal utility and marginal costs as factors. Alfred Marshall, the father of modern microeconomics (as taught at the undergraduate level), formalized the relationship between these two side and served as an effective integrator of economic ideas around the turn of the twentieth century. Modern economics has taken these ideas and successively applied more and more formalism (i.e., mathematics) in order to create context-free and generalizable economic models. ${ }^{31}$

As one sees from the preceding discussion, the notion of value in design may transcend classical economic definitions, since "value in exchange" may not be appropriate to non-commodity goods that are unique and rarely exchanged. Over the history of economics, the underlying definition and conception of value, in particular related to valuation, or "pricing," has evolved from one related to supply-side (what are the costs and factors of producing something?) to demand-side (what is the usefulness of the object, independent of how it was produced?) to a mixture

\footnotetext{
* As an example, consider the collection of an aggregated set of requirements from a group of possibly disparate stakeholders (e.g., "users"). Implicit in systems engineering practice is that meeting these requirements, as well as schedule and cost goals, results in a "valuable" system. But each requirement is a distinct need from perhaps a different person. This implicitly treats the group of individuals as one "meta-person" whose satisfaction will be met from meeting the sum of the requirements. An indirect "weighting" of stakeholders can occur through the number of articulated requirements per person, if all requirements are treated equally. An alternative to an egalitarian principle is one where different stakeholders have different "importance" and therefore assigned a weighting through requirement prioritization, constraints on number of requirements, or even through an explicit weighting in a utility function.
} 
of both (what is the usefulness, scarcity, and resource-intensiveness of an object?). It is not the intent of this paper to recount the historical progression of the meaning of value, however it is important to note that the definition of value, even as one of the essential conceptual underpinnings of economics, has had a complex and nuanced interpretation over time. ${ }^{32}$

In addition to the myriad "schools" of economic thought that have existed over the years, embodying various philosophical assumptions and bases, such as the "Chicago school"33," it is useful to consider two instructive categories of thought that impose justification on what is considered "good": Teleology and Deontology. Teleology $^{34}$ (or Consequentialism) is where the outcome justifies the meaning of "good", i.e., the "ends," and Deontology ${ }^{35}$ is where rules, or the "character," of the endeavor justifies the meaning of "good", i.e., the "means." For example, Teleology would suggest value comes from "good" end result systems, while Deontology would suggest that value comes from the "good" process of creating the end result systems. One might even go so far as to say that this tension reflects the product vs. process focus in the development literature. Taking an agnostic position on this issue, value could be created from either or both sources. For example, one might find it "valuable" to have a system that provides precision navigation and timing information to any point on the globe. A different, or even same, person may find it "valuable" to award contracts to multiple organizations in order to promote competition and maintain a healthy industrial base.

Given the discussion thus far begs the question of whether there is such a thing as "intrinsic value" of a system design. As mentioned earlier, the value of an item cannot be measured solely by the total worth of resources that went into its creation (supply-side). The problem with only considering resources (e.g., budget and schedule) for determining value is the neglect of the "satisfaction" (demand-side) aspect of value. Additionally, a large disconnect between the amount of resources put into a system and the usefulness of the system is often seen by the aerospace industry. That is, one could spend many person-years and dollars developing a system, only to find it utterly useless in raising the satisfaction level of its user-base (e.g., the original Iridium system, or any other "failures" in the 1990s satellite constellation craze, or other systems that took too long to reach operations, finding themselves irrelevant in their ultimate operational context). This then suggests that value for design should incorporate the competing "subjective theory of value." This theory holds that in order to have value, a good must be both "useful" (i.e., satisfying to both the supplier and the demander) and "scarce" (i.e., special or unique). Coupled with consideration of efficient allocation of resources needed for its creation, the use of "value" in the aerospace community aligns very well with these criteria. Since aerospace systems are typically costly, in terms of dollars, effort, time, and possibly political will, to develop, they are "scarce" in the sense these systems are not considered ubiquitous. The second criteria, being "useful," is the ultimate aim of the systems engineering and acquisition process, especially developing good requirements capture and validation, as well as the development of contracts that make participation worthwhile for the aerospace industry. In summary, in order to create "value" to someone, one must balance and increase the net level of (1) satisfaction (i.e., utility), with (2) available resources, while addressing (3) its degree of importance.

\section{The Foundation of Value-Centric Design Methodologies: Economics}

Supposing that an economics perspective is still a useful approach to defining value in order to drive design, then it is necessary to explicitly point out the assumptions needed to apply economic methods. In particular the issue arises around the connection between "value in use" and "value in exchange," Price-setting, specifically the willingness to exchange money for a good or service, relates fundamentally to the "value in exchange."

\section{A. Traditional Economic Assumptions}

The world of design is an interesting application for economics-based approaches, in that it violates most common assumptions used in neoclassical economic approaches. For example, design typically incorporates a "supplier" and a "demander" as in the case of economic markets. However, the "supplier" in this case, such as an aerospace manufacturer, has a direct conversation with the demander, such as the Department of Defense, in order to better assess how the demander will perceive the usefulness of the ultimate system to be exchanged. The terms of the exchange (i.e., what scarce resources are exchanged for what level of satisfaction) are specified through contractual means, thereby pre-specifying acceptability levels and expectations on "value." For technically

\footnotetext{
* The Chicago School is associated with techniques of academic economists of the "neoclassical" tradition (e.g., marginal analysis) that became identified with the economics department at the University of Chicago. The school emphasizes "the power of neoclassical price theory to explain observed economic behavior and the efficacy of free markets to best allocate resources and distribute income."
} 
challenging or unique aerospace applications, the definition of expectations of the demander (the expected "value in use") is often ill-defined, either because the expectation is based on ambiguous goals or the desire for a new, possibly unproven capability (such as enabled by immature technologies or untested collaborations between systems or organizations). In a typical market studied by economists, such direct conversations usually do not occur. Instead, demanders "reveal" their preferences through their decisions to pay a price (in terms of dollars, usually, though it could include time or effort as well) through purchasing, and therefore demanders are usually "pricetakers." However, in the typical aerospace case, the choice of which product to purchase can be degenerate, if the product is an evolving "concept" that is the subject of the design effort of the supplier. If the supplier is unable to meet the prior level of expectations set forth in requirements and/or contracts, then the "value" of the system is reduced to the demander. The "value" of the system to the supplier, however, may be contingent upon other factors, not necessarily specified in the contract or requirements. Any shift in resources required to develop a system, or reduction in performance, would result in lower levels of satisfaction in the demander. In a competitive market, this could result in a change in the terms of exchange, for example the decision to purchase an alternative system.

The aerospace context itself is not unique in its violation of typical economic markets assumptions. The models of aggregate demand for neoclassical economics assume a "rational, utility-maximizing" individual, which psychologists began to question in the late 1970s. ${ }^{16}$ Recognizing that humans in fact have limited cognitive capabilities, are affected by biases, and tend to rely upon heuristics for decision-making, the field of behavioral economics married insights of individual thinking from psychology with the logic of markets from economics. ${ }^{17}$ Such knowledge can be used to manipulate markets, for example by selectively controlling access to information such as "hidden add-on prices" 36 , thereby altering the landscape of "value" exchange due to psychological limitations. A related field, behavioral finance, applies psychological insights, such as risk aversion and short time horizons, to predict and explain deviations from efficient markets. ${ }^{37}$ The field of behavioral economics is still maturing ${ }^{38,39}$, but the impetus for the field was the recognition that human psychological perceptions drive markets, both at the aggregate level (e.g., financial markets), as well as the level of the individual (e.g., high-end consumers). In addition to neoclassical economics, emerging methods from behavioral economics can be leveraged and applied to help value and guide system design and selection.

\section{B. Assumptions for Monetizing Value}

As the fundamental currency of economics, dollars are used as a common metric in economic models. The notion of monetizing value is similar to the problem of developing a "theory of pricing," that is, determining the amount of money that is (should be) exchanged between a demander and a supplier in return for good(s) exchanged. In order to perform this calculation, it has been recognized that a simple causation relationship between costs, utilities, and prices cannot be determined, but rather emerges from a complex interrelationship among these concepts. ${ }^{29}$ In order to turn value into a dollar figure, one must have a consistent "measure" of both value and dollars. Possible violations of this consistency include: the existence of multiple perceivers of value, with distinct perspectives (e.g., the problem of aggregating across individual preferences mentioned earlier), temporal considerations (e.g., the difference between achieving value today versus tomorrow), and constraints on types of dollars expended (e.g., the "colors of money" problem where budget allocations put constraints on how dollars can be spent up to certain limits). If a consistent measure for both dollars and value does not exist, then a consistent transformation from one to the other is not possible. One can impose assumptions in order to make this transformation work, however, and this will be described in Section IV.

\section{Possible Violations for Aerospace Context}

A dilemma that faces engineers and analysts seeking to apply economic approaches within the aerospace context involves the fact that many assumptions in economic theories are violated in the aerospace context. The more specialized a system, and the more resources required to construct the system, the more a market deviates from a competitive market, which requires many suppliers, demanders, exchanges, and access to information. In the aerospace case, the resulting market has a reduction in the size of the potential demanders for the system, as well as the potential suppliers. In the extreme example of most aerospace systems, only governments can afford the dollars, time, and effort required to develop a system, and only a few specialized companies possess the labor and capital in order to create the system. The interactions between monopsonies (single demander) and oligopolies (few suppliers) is a much more complicated case of market dynamics than what is intuited through competitive markets as taught in most economics courses and methods. In order to apply economics methods to the aerospace system design problem, one must take into account the different dynamics at work, especially as related to price-setting. 
Being a "price-taker" is often a characteristic of a demander in a competitive market. In such marketplaces, the customer has to pay the price that the supplier offers". The theory goes that the customer will pay a price only if the "value" of the good to the customer exceeds the net loss of the price paid. But how to set the price for an aerospace product if only one (or few) customers exist? The supplier may choose not to create the product in the first place if the supplier does not see the "value" in such an exchange. Therefore, the dilemma of creating valuable aerospace products falls on properly crafting an exchange that will result in value to both the supplier and demander in a small market (where few exchanges will occur). As mentioned in the Teleological vs. Deontological interpretation of value, one must look to both the "ends" and the "means" in order to propose value opportunities. For example, the demander may want value in terms of benefit in end use, while the supplier may want value in terms of consistent employment and low-risk contracts.

\section{Choosing the Appropriate Operationalization of Value}

Given the foregoing discussion, a number of issues have arisen regarding the appropriate operationalization of value. On the one hand, the utility, as determined by a demander, is an operationalization of value in use, while on the other hand the "price" is an operationalization of the value in exchange between a demander and a supplier. The determination of such a price, depending on the market however, may not be well specified and can readily fall victim to tautological arguments where price is determined by demand, which is determined by supply, which is determined by demand,. In such cases, an arbitrary starting point (such as prior exchange values) can be used to begin the bargaining. As has been pointed out in the previous section, however, the determination of price through market mechanisms is dependent on the number of suppliers, demanders, possible exchanges, resourceintensiveness, and scarcity of "goods," which may not be appropriate in the aerospace context when the number is small. In this extreme market case, economic theory does not provide clear suggestions on how to best determine price. Therefore, it is with caution that the aerospace valuation engineer chooses his method for quantifying the "value" of a design for a demander, or a supplier.

In order to best determine the appropriate operationalization of value, the valuation engineer should first identify the type of market in which the system will be evaluated. For instance, if the system has many demanders and many suppliers, then traditional market economics will apply and pricing can be determined "by the market" through competition. In such cases, it is not necessary to know the individual preferences of demanders since enough of a market exists and the supplier can get good enough market share by providing a useful system that enough demanders are willing to pay for at a particular price ${ }^{\dagger}$. If, however, the number of demanders, suppliers, or exchanges is small in number, the stakes are raised in terms of "getting terms right" in order to have an exchange occur. In these cases, understanding the utility, resource, and importance expectations of both the supplier and demander is essential in order to maximize value creation. An operationalization of value for the supplier is to identify the demanders as explicitly as possible and attempt to elicit the value expectations for each demander. Such demanders are often called stakeholders, and meeting their needs (value in use along with resources for their realization), along with supplier needs ${ }^{\ddagger}$, maximizes the chances of creating a valuable system design. The rest of the paper will examine several mathematical methods for operationalizing value in order to propose valuable system designs to a stakeholder of interest.

\footnotetext{
* In such markets, suppliers do not need to care about the satisfaction of particular demanders since it is the aggregate behavior of the market through many exchanges that result in value to the supplier. As the number of exchanges and demanders go down, the supplier must care more and more about the particular demand preferences of the remaining market players. Therefore the more information the supplier can glean about the preferences of the demander, the more the supplier can cater to, or at least anticipate, the "willingness to pay" of the market. This is the motivation for identifying the needs of a small market in order to maximize value to both the supplier and demander. ${ }^{\dagger}$ This does not mean that the supplier/system designer should neglect the expectations of the demanders (i.e., users or customers), but rather it becomes less and less important to satisfy each one individually since other exchanges can occur if one demander decides to not participate. Market research can be performed to understand the aggregate preferences of a market in order to target "useful" systems and expectations on price.

* For simplicity sake, the rest of the paper will focus on demand-side value expectations (i.e. value as perceived by stakeholders), though the supplier (i.e. aerospace system designer and his firm) should also understand its value expectations as well (e.g., profit margins, contract stability, alignment of organizational competencies).
} 


\section{Value-Centric Design Methodologies}

Value-driven design is implemented through what have commonly been referred to as Value-Centric Design Methodologies (VCDMs). The fundamental premise of these VCDMs is that they attempt to quantify the "value" of an (engineering) system, and subsequently they each have a unique interpretation, quantification, and representation of the term value. Given the desire to employ a VCDM that is able to capture the aforementioned value of a system, as perceived by the stakeholder(s) of the system, it becomes crucial to recognize the manner in which each VCDM quantifies and defines value. This is necessary to avoid employing a VCDM that does not conform to a given stakeholder's interpretation of value in a system. For example, if a stakeholder perceives a system's value to be a function of both performance and cost, then they would not be satisfied with a VCDM that quantifies, and therefore assumes, the value of a system is equal to its respective profit. Regardless of the VCDM employed and its ensuing interpretation of value, fundamentally the motivation for using a VCDM is the provision of a consistent, consensus building tool for making educated (value-driven) decisions about system design, not to provide absolute measures of value. Without such consistency, trends in value cannot be preserved amongst multiple stakeholders and/or system designs, something that eradicates confidence in conclusions as to the most valuable system design.

Of equal importance to the conformance of a VCDM to stakeholder perceived value are the inherent assumptions in a given VCDM. Assumptions form the credibility, or lack thereof, of a given VCDMs capability to quantify a system's value. Therefore, in choosing a VCDM, it is important to balance the desire to quantify value using the output of a given VCDM to the liberalness, or lack thereof, of the assumptions made by the VCDM. Therefore, the ideal VCDM is one in which interprets and quantifies value directly as perceived by stakeholders and furthermore makes assumptions enabling the VCDM to quantify that value, credibly. With this in mind, the ensuing sections succinctly discuss several of the more prominent VCDMs employed in an engineering context.

\section{A. Net Present Value (NPV)}

Net Present Value is a method often used for the financial appraisal of physical assets and can subsequently be used to quantify the monetary "value" of a system, if a system's respective value is interpreted as being cash flow or profit less costs over time; note, cash flow may be a negative quantity. As such, NPV is frequently employed as indicating measure of how much an investment in an asset (e.g., an engineering system), adds to the monetary net worth of the stakeholder(s) making that investment. Specifically, NPV achieves this by quantifying the discounted cash flow generated by an asset over time. Discounted cash flow is an estimation of future cash flows that an asset will generate, which are then discounted so that they have present-day value. Subsequently, a discount rate is used in NPV calculations to account for the real discount and inflation rate in a given asset's future cash flow. Therefore, value, as interpreted, quantified, and represented by NPV, is discounted cash flow. Fundamentals of Corporate Finance provides an excellent discussion of NPV theory and applications in the finance market, which can be readily extended to valuing engineering systems, and an application of NPV for the "valuing" of spacecraft can be found in A Modular, High-Fidelity Tool to Model the Utility of Fractionated Space Systems. ${ }^{7,22}$

1. Governing Equation

For a given asset, NPV is quantified in monetary terms (e.g., USD). The governing equation for NPV is given by Equation $1 .^{40}$

$$
N P V=D_{o}+\int_{t_{j}}^{t_{k}} \frac{D(t)}{(1+r(t))^{t}} d t \sim D_{o}+\sum_{t_{j}}^{t_{k}} \frac{D(t)}{(1+r(t))^{t}} \sim D_{o}+\sum_{t_{j}}^{t_{k}} \frac{D(t)}{(1+r)^{t}}
$$

Here, $D_{o}$ is defined as the cash flow expended before time $t_{j}$ (i.e., the initial investment); $D(t)$ is the net cash flow (revenue minus cost) at time $t ; r(t)$ is the discount rate (i.e., rate of return on future investments) at time $t$; and $\left\lfloor t_{j}, t_{k}\right\rfloor$ represents the time interval over which the NPV is quantified. Ideally, the variables in the NPV equation are known to the limit that they become continuous functions in time, however, most often the simplest form of the NPV equation is used (furthest to the right in Eq.(1)). This simpler form of the NPV equation subsequently assumes a constant discount rate and discrete time steps such as monthly. Intuitively, the smaller the time step, the more descriptive a NPV calculation is, but also the more predictive fidelity required in determining the NPV equation variables in time.

If the NPV of an investment over a given time period is positive, zero, and negative, it implies that, the investment yields a positive, zero, and negative cash flow respectively. A NPV of zero is a special case in which the discount rate for the investment is the internal rate of return on the investment, thereby providing the "break-even" discount rate. Regardless of the NPV sign, its ability to predict profit for investors depends entirely on their respective financial situations. 
AIAA Space 2010

\section{Assumptions and Limitations}

There are several notable assumptions made in a NPV analysis and these become the inherent limitations of employing NPV as a VCDM. Note that the assumptions mentioned hereafter are not intended to encapsulate every assumption made in NPV but rather enumerate only the major assumptions. The first of these is that a given NPV analysis, which is quantified as a discounted monetary return on investment over time, assumes that the stakeholders for a given system (asset) perceive the value of that system only to come from monetary return. This assumption thereby causes NPV to fail to account for any other potential sources of (non-monetary) value a system provides to the stakeholders; this point is particularly well articulated in literature. ${ }^{18}$

The second assumption made in a NPV analyses pertains to the computation of NPV, and this assumption is that the variables in the NPV equation can be credibly (i.e., appropriately and accurately) predicted and thus quantified, for a given system. This assumption emphasizes the highly uncertain nature of these variables and therefore potential for a given NPV analysis to require extensive predictive insight into the respective market for a system. As such, it is extremely difficult to determine a discount rate and cash flow such that they are accurate to the true stochastic, evolutionary (emergent) nature of a system's respective revenue market over time; this representation becoming especially inaccurate when the discount rate and/or cash flow is held constant. The implications of this second assumption are that further, more detailed, assumptions must be made for calculating the cash flow and discount rate at a given point in time, for a given system. This in turn requires extensive market predictions to be made for a potentially volatile, future financial market, which include market demand curve(s), revenue (pricing) structures, monetary inflation/deflation, and return rates on investment.

The remaining set of assumptions inherent to NPV analyses are grounded in psychology and economics. ${ }^{18}$ In particular, given its additive form, NPV necessarily assumes the existence of mutual preferential independence amongst its respective "attributes", aka independent variables in time. Within the psycho-economic domain, another assumption NPV embodies is that a set of independent variables can be quantified and then combined under certainty, that is, the independent variables are determined from a tradeoff between pairs of certain consequences and hence outcomes. Given these two assumptions, NPV thus fails to capture the intrinsic nature of decisionmaking under uncertainty given its assumption that in the present, all attributes of a system (and thus cash flow) are known with certainty. And this last point ultimately leads NPV to deviate significantly from accepted psychoeconomic tenets for stakeholder behavioral decision-making, in the context of valuing assets (e.g., systems). ${ }^{18,41}$

Lastly, as with MAUT and CBA, inherent in NPV is an inability to aggregate the preferences (pertaining to the benefits of a system) of more than a single stakeholder; this being best summarized through Kenneth Arrow's General Possibility Theory. ${ }^{42}$

Consequently, all the assumptions made in employing NPV as a VCDM lead to a compounding error in the NPV equation and, if applicable, continued nonconformity to the stakeholder perceived value in a system. In addition, as mentioned previously, NPV also has other sources of error, specifically with regard to projected versus actual cash flows, forecasting risk, other sources of value not captured by NPV calculations, risk in using discounted cash flow, hidden costs, and the incremental (discrete) nature of the NPV metric characterization. ${ }^{22,40}$ While NPV is no doubt a well-vetted and useful tool in economics, ultimately, the assumptions inherent to NPV are best summarized as leading to the following predicament:

...most of the time we can't actually observe relevant market value. Instead, we estimate it. Having done so, it is only natural to wonder whether our [NPV] estimates are at least close to the true values... The first possibility is that the project really does have a positive NPV. That's the good news. The bad news is the second possibility: A project may appear to have a positive NPV because our estimate is inaccurate... [And] if we conclude that a project has a negative NPV when the true NPV is positive, we lose a valuable opportunity. ${ }^{22}$

\section{B. Multiple Attribute Utility Theory (MAUT)}

Expected utility theory is a respected economic theory that enables the numerical quantification of a benefit (attribute) provided by, in relevance to this work, an engineering system. ${ }^{43}$ More generally, utility theory provides a means to quantify the benefit produced by a given outcome, this outcome in turn resulting from a system's inherent functionality, for example, the EOS Aqua satellite's six instruments' bandwidth and data correlation (cross registration) capabilities. Utility theory was developed as a potential improvement to indifference theory and the desire to rank preferences amongst a set of outcomes numerically rather than qualitatively, the latter being the extent possible using indifference theory. ${ }^{44}$ Subsequently, for the past fifty years, utility theory has become a useful construct for consistent decision-making, specifically in the context of a set of uncertain outcomes such as potential benefits yielded by a system. ${ }^{18,44}$ 
In the context of a system, while utility theory is based on a single benefit (attribute) of a system, often there are multiple benefits of interest for a particular stakeholder of that system. Thus, multiple attribute utility theory (MAUT) is often used instead because of its ability to rank systems on the basis of their aggregate benefit (called MAU), relative to a pre-determined set of attributes, which each characterize a desirable (or sometimes an undesirable) aspect of a system. ${ }^{18}$ Subsequently, MAUT allows for the quantitative aggregation of monetary, but more often non-monetary, stakeholder preferences for, and hence stakeholder perceived value of, a given system. In addition, analogous to utility theory, MAUT quantifies and thus ranks systems based on their respective benefits and a stakeholder's preferences are characterized by the MAUT metric under uncertainty - a notable feature of MAUT given the naturally uncertain context in which decisions are made by stakeholders. This feature of MAUT is specifically manifested by the MAUT representation for a given system, namely, a multiple attribute utility curve, which in turn is derived through a set of probabilistic lotteries (scenarios) based on system attributes, rather than, using certainty equivalents as is done for value functions, NPV, and CBA. Therefore, value, as interpreted, quantified, and represented by MAUT, is the aggregation of (non-monetary) benefits relative to the monetary cost of obtaining those benefits. In some recent applications of MAUT, cost is not included in the attribute set in order to provide a direct benefit-cost comparison, however, it can be included in the attribute set if desired. ${ }^{45,46}$

The motivation for using MAUT in the valuation of engineering systems is due to it being the more appropriate alternative to value functions, for the ranking of alternatives based on multiple sources of non-monetary value under uncertainty. ${ }^{18,47}$ This motivation is further substantiated given the inherent inability for stakeholders to assign a monetary value to an outcome (or set of outcomes) in the first place. ${ }^{47}$ As such, given the inherent advantages of MAUT, specifically over value functions, in the domain of space systems, the use of MAUT for value-centric design has been significantly motivated in academia as well as industry for valuation of space systems. ${ }^{1-4,6,8-13}$

\section{Governing Equation}

The governing form of the MAUT equation is dependent on the assumptions made about the stakeholderperceived independent nature of a system's attributes used to quantify the MAUT. As more assumptions are made, and thus more likely to deviate from the desired decision-making behavior of stakeholders, the MAUT governing equation becomes numerically simpler to derive and compute. The most useful form of the MAUT is given by Equation 2; this form of the MAUT equation assumes mutual utility independence, a weaker (less restrictive) assumption than mutual additive (preferential) independence ${ }^{18}$, as is assumed for discounted cash flow methods such as NPV and CBA. This allows for consideration of substitution and complement affects among attributes, thereby enabling MAUT to conform to the desired behavior of stakeholder decision-making more accurately than the VCDMs having governing equations that assume mutual additive (preferential) independence.

$$
K \cdot U(\hat{X})+1=\prod_{i=1}^{n}\left(K \cdot k_{i} \cdot U\left(X_{i}\right)+1\right) \quad \text { where, } \quad K=-1+\prod_{i=1}^{n}\left(K \cdot k_{i}+1\right)
$$

Here, $K$ is the normalization constant; $U(\hat{X})$ is the aggregate utility value for the multiple attributes and their respective utilities, $U\left(X_{i}\right) ; k_{i}$ is the $\mathrm{i}^{\text {th }}$ corner point which is a swing weighting factor for the $\mathrm{i}^{\text {th }}$ attribute, $X_{i}$; and $n$ is the total number of attributes. The MAUT function, $U(\hat{X})$, is almost exclusively quantified and represented on a scale from 0.0 to 1.0 , where a MAUT value of 0.0 and 1.0 is the least and most desirable respectively. However, although the $[0.0,1.0]$ scale is conventional, it is entirely arbitrary and hence any scaled range preserve the functionality of MAUT (e.g., [-4.1, 56]). The MAUT function therefore provides a means to aggregate $n$ monetary and/or non-monetary benefits produced by a system into a single number that can then be used to conveniently rank, in terms of desirability, numerous systems across these $n$ benefits (attributes). A discussion pertaining to the derivation of the MAUT function for a given stakeholder and preference structure is not given herein, but it is treated in detail in several literature sources. ${ }^{18,48}$

\section{Assumptions and Limitations}

While MAUT has proved itself a useful value-centric methodology, it also makes several key assumptions and thus suffers from notable limitations. The first set of these assumptions, which are implicit to deriving a MAUT function, leads to the MAU being a non-ratio, dimensionless, bounded cardinal scale. This thereby precludes quantitative ratios between any two MAU values from being meaningfully calculated. Additionally, this has notable ramifications for using MAUT as a valuation tool as it implies that while MAUT can be used to provide a ranked ordering of MAU values and hence systems (e.g., system A is more desirable than system B since it has a larger numeric MAU value), the boundedness of the scale limits appropriate statistics that can be calculated. Thus, while MAUT aggregates and compares systems based on a set of benefits, alone, it cannot provide descriptive insight into quantitative disparity in those benefits between systems. 
The second notable assumption inherent in MAUT leads to its inability to "reasonably" aggregate the preferences (pertaining to the benefits of a system) of more than a single stakeholder; this dilemma is best summarized through Kenneth Arrow's General Possibility Theory. ${ }^{42}$ As a response to Arrow's proof for the nonexistence of a social welfare function, Ralph Keeney and Howard Raiffa provide several methods for integrating multiple stakeholder preferences into a MAUT function ${ }^{18}$, however, note that these do not absolve MAUT from the issues established through the General Possibility Theory.

Another assumption and ensuing limitation of MAUT is that it quantifies the aggregate benefit of a given system using an abstract dimensionless metric, rather than a more intuitive scale, such as dollars, which tends to resonate poorly with stakeholders. For a given system, if one qualitatively compares a MAU level to its associated cost, it does provide a proxy for value, however, at its very basis, MAUT does not directly quantify the value of a system, rather, it tries to quantify the perceived utility, and this should be recognized. This assumption forms perhaps the common basis for cases made against the use of MAUT as a VCDM, despite its ability to value systems based on a any number of benefits without the need for mapping different cardinal scales to one another, something not possible using "traditional" cardinal valuation techniques such as NPV and CBA.

As was cited previously, MAUT (in its most common function form) assumes mutual utility independence, and although less restrictive than mutual additive (preferential) independence, it still does not completely conform to the actual observed behavior of stakeholders and their respective decision-making under uncertainty. Thus, it is not accurate in providing a description for a decision-making characterization of stakeholder behavior, but is an improvement over methods such as NPV and CBA. There are also assumptions regarding the attribute set in applying MAUT. In particular, an attribute is a characteristic of a spacecraft (system) assumed to embody useful/desirable stakeholder objectives to and adhere to the five properties of an attribute set established by Keeney and Raiffa: complete, operational, decomposable, non-redundant, and minimal. ${ }^{18}$ And lastly, MAUT, in its traditional application, assumes that over a given period of time, the stationary assumption holds, implying that preferences do not change in time. ${ }^{18}$ Analyses such as NPV and CBA also suffer from this assumption; however, in contrast, this has been, in part, addressed for MAUT through the development of Dynamic Multiple Attribute Tradespace Exploration and Epoch-Era Analysis. ${ }^{45,49,50,51}$

\section{Cost-Benefit Analysis (CBA)}

Cost-benefit analysis (CBA) is a prescriptive methodology that quantifies the net benefits yielded by a system relative to its respective net costs. ${ }^{20,52}$ CBA serves as a useful value-centric tool for cardinally weighting the positive and negative effects of various outcomes and combining them into a single metric. As such, CBA encompasses a vast domain of specific methodologies, each having their own unique CBA prescription. However, most often the costs and benefits, per the CBA prescription, are quantified for a given system into a single, monetary metric, this thereby requiring that all direct costs and benefits associated with the system be transformed into monetary units. However, any cardinal scale may be used in CBA. As a result, discounted cash flow is implicit to $\mathrm{CBA}$, as it is for NPV, for the assignment of monetary values for the costs and benefits of a system, and thus the limitations of NPV are inherent to CBA. CBA and NPV are often used similarly, but CBA differs from NPV because it discretizes and monetizes each attribute of a system, regardless of whether it contributes to the revenue of the system, which is of particular relevance in missions having benefits clearly not mapped to revenue or missions generating a negligible (if any) amount of revenue. Ultimately, value, as interpreted, quantified, and represented by CBA, is single, monetary metric representative of the difference between a set of monetized benefits and their respective monetary costs. Cost-Benefit Analysis provides an excellent discussion of the topic, and an overview and application of CBA, in particular with regard to transportation systems, is given in Using Multi-Attribute Tradespace Exploration for the Architecting and Design of Transportation Systems. ${ }^{19,20}$

1. Governing Equation

Given the reliance of CBA on discounted cash flow, the governing equation for CBA most often assumes the non-integral (summation) form shown in Eq. (3). The only difference between Eq. (1) and Eq. (3) is that the latter uses the difference between monetized benefits and costs instead of cash flow alone, however like NPV, these need to be determined from a transfer function (or set of functions), given that benefits are most often not in monetary form. The most succinct and generalizable governing equation for CBA is given be Equation 3; note, there is an continuous (integral) form of this equation akin to Eq. (1). ${ }^{20}$

$$
C B=\left(\sum B_{o}-\sum C_{o}\right)+\left(\sum_{t_{j}}^{t_{k}} \frac{\sum B(t)}{(1+r)^{t}}-\sum_{t_{j}}^{t_{k}} \frac{\sum C(t)}{(1+r)^{t}}\right)
$$


Here, $C B$ is the resulting monetary benefit of a system relative to its respective cost (i.e., value); $B_{o}$ and $C_{o}$ are the initial monetary benefit and cost of the system respectively, if applicable; $r$ is the discount rate (i.e., rate of return on future investments), assumed constant; $\left[t_{j}, t_{k}\right\rfloor$ represents the time interval over which the cost-benefit is quantified; and $B(t)$ and $C(t)$ are the monetary benefits and costs yielded by the system at a given point in time, $t_{i}$. In Eq. (3), it is evident that CBA aggregates a set of costs and benefits across a given time interval and that each of these costs and benefits must be in cardinal (most often monetary) terms. Subsequently, one of the inherent challenges in CBA is how to monetize and appropriately normalize all of these benefits and costs to a common single cardinal, monetary scale.

\section{Assumptions and Limitations}

Given the dependence of CBA on NPV, or more generally discounted cash flow, it inherently contains the assumptions and subsequent limitations previously cited for NPV. It should be noted, however, that unlike NPV, CBA it is able to aggregate and value a system along multiple dimensions (i.e., costs and benefits), the aggregation of multiple benefits making it similar to MAUT. However, in addition to the assumptions made by NPV, CBA makes several other unique assumptions. ${ }^{20}$ The first assumption is that a system's respective benefits can be monetized and furthermore that the costs and benefits of that system can be mapped to a single cardinal (monetary) scale, accurately. Subsequently, this monetization requires assumptions that may be extremely liberal (and sometimes unacceptable) in their interpretation of valuing of goods and services.

Secondly, CBA necessarily discounts non-monetary and monetary goods and services, thereby requiring assumptions to be made about future markets and the monetary worth of goods and services - a highly uncertain and difficult set of predictions to make. This assumption highlights the vast area for interpretation in using CBA, in particular in the development of transfer functions to assign monetary value to benefits produced by a system. The third assumption arises from CBA truncating and therefore losing information about the distribution of costs and monetized benefits in time, which may be of importance to decision-makers interested in the influence of specific costs on the resulting CBA and subsequent decisions made. Another notable assumption made by CBA is that it is appropriate to combine a potentially diverse set of costs and benefits and normalize them to a unifying cardinal scale, which becomes a decision-makers only datum for evaluating a set of outcomes (systems). This assumption in turn has significant ramifications for the valuing of a system, specifically with regard to equating and comparing system attributes that can be easily monetized (e.g., material cost of a system) to those that simply cannot be monetized (e.g., spacecraft pointing-tolerance). Lastly, as with MAUT and NPV, inherent in CBA is an inability to aggregate the preferences (pertaining to the benefits of a system) of more than a single stakeholder; this being best summarized through Kenneth Arrow's General Possibility Theory. ${ }^{42}$

CBA can therefore be thought of as a bridge between NPV and MAUT in that it employs a NPV-type analysis to monetize the costs and benefits of a system but deviates from NPV and likens itself to MAUT in its ability to incorporate and combine multiple benefits into a single numeric value. This conclusion, however, enumerates perhaps the most significant shortcoming of CBA, which is the plethora of assumptions required to monetize, and subsequently normalize to a common scale, the costs, and benefits of a system.

\section{Other: Cumulative Prospect Theory, Value Functions, Analytic Hierarchy Process, and Technique for Order Preference by Similarity to Ideal Solution}

For completeness, it is necessary to mention alternatives to the previously described VCDMs, and these alternatives provide perspective on the advantages, assumptions, and disadvantages of these aforementioned VCDMs. The following discussion will therefore just briefly touch on a few of the prominent alternative VCDMs and not explore them beyond introducing their purpose in the context of value-centric design. Specifically, the four alternative VCDMs are (Cumulative) Prospect Theory (CPT), Value Functions (VFs), Analytic Hierarchy Process (AHP), and Technique for Order Preference by Similarity to Ideal Solution (TOPSIS); note, this list is not exhaustive. An excellent discussion and comparison of Prospect Theory, Utility Theory, and Value Functions is in Value Functions Versus Utility Functions. ${ }^{15}$

\section{Cumulative Prospect Theory (CPT)}

The first of these alternative VCDMs, Cumulative Prospect Theory (CPT), was developed by Amos Tversky and Daniel Kahneman; CPT is an improvement upon Prospect Theory, also developed by Kahneman and Tversky in the late 1970's. ${ }^{16,17}$ Specifically, CPT is a descriptive-based tool developed in response to the belief that the normative expected utility theory does not appropriately characterize decision-making under uncertainty. ${ }^{23}$. Subsequently, CPT is directly aimed to modify utility theory to account for observed violations of expected utility theory, as developed by John von Neumann, but make as few modifications as possible. ${ }^{44}$ The result of CPT is evident in its respective loss-gain or "S" curve, which forms a value function representing the behavioral characteristics of

12

American Institute of Aeronautics and Astronautics 
stakeholders under uncertainty, much as utility theory does, but instead in monetary terms. Literature offers many good sources for understanding CPT and its application. ${ }^{23,53,54,55,56}$

In terms of limitations, CPT shares many of those found in MAUT, however, it deviates from MAUT in its descriptive rather than normative nature and thereby quantification of stakeholder preferences in descriptive, monetary terms. Consequently, CPT necessarily suffers from the assumptions and resulting limitations created by monetarily valuing goods and services such as those observed in CBA and NPV.

2. Value Functions (VFs)

Value functions can be broadly categorized as functions that quantify, in any cardinal unit of measure (although usually in monetary units), the intrinsic value of a system, which in turn is determined under certainty, and VFs may be ascertained so that they exist as an ordinal or cardinal function. ${ }^{15,18}$ Furthermore, this property of value functions implies that utility functions are value functions but the converse is not necessarily true. In short, VFs capture the elicitation of stakeholder preferences about the outcome of a situation, which is known with certainty, in terms of how much they would be willing to pay to have that outcome occur or not occur. Hence, VFs most often assume a monetary form and embody a stakeholder's change in wealth relative to a given set of outcomes. Like, MAUT, VFs can incorporate (combine) multiple sources of "value", which are derived from multiple attributes, however, unlink MAUT, through stakeholder elicitation, VFs map a stakeholder's preference structure across a set of attributes (with their own cardinal scales) to a single cardinal scale, thus implying that such a mapping exists. VFs, as are found in literature, are often additive in nature and thus make the assumption of mutual additive (preferential) independence amongst the various attributes constituting the value function as NPV and CBA do. ${ }^{18}$ Therefore, from a psychoeconomic standpoint, the main difference between VFs and MAUT is that VFs assume mutual additive (preferential) independence (not mutual utility independence - a much weaker, less restrictive, assumption). In addition, VFs and MAUT differ in the former's quantification of value in explicit monetary terms and they also $d o$ not characterize behavioral decision-making under uncertainty as is evident by their derivation. ${ }^{18}$ Hence, situations (in time) that involve a set of outcomes, each having a certain probability distribution or probability of occurrence that are dependent on a set of attributes, can be appropriately characterized by MAUT and not by VFs, thus the motivation for MAUT.

3. Analytic Hierarchy Process (AHP) and Technique for Order Preference by Similarity to Ideal Solution (TOPSIS)

It is worth mentioning two other alternative approaches to valuing systems and options for these systems, in particular AHP and TOPSIS. The former, AHP, is a method for systematically decomposing a system into a hierarchy of desirable attributes that aggregate to an overarching goal. The manifestation of this is a decision tree (or matrix) where the highest order of the tree/matrix is the goal to be achieved and logically disseminating from this are a set of decisions, or attributes, where each attribute aggregates a set of attributes that collectively comprise that attribute at the next higher level in the hierarchy. Through a simple algorithm and appropriately weighting of each ensuing node of the decision tree via pairwise comparisons, this hierarchy is then used to mathematically inform decisions as to the most "valuable" system or decision meeting the overarching goal. Ultimately, AHP provides a cardinal measure for decision-making. A detailed explanation of this method can be found in Decision Making The Analytic Hierarchy and Network Processes (AHP/ANP)..$^{57}$

TOPSIS is an ordinal, aggregate measure of utility (benefit) derived from a set of attributes. The TOPSIS method entails normalizing and weighting the values of a set of attributes corresponding to numerous alternatives (scenarios or outcomes). This information is then used to compute the "distance" of the current set of attributes for a given system in terms of its normalized "distance" from the positive and negative ideal solution. Here, the concept of distance is in relevance to the cardinal scales of each attribute. Ultimately, this yields a rank-order for a given set of attributes (derived from a system). TOPSIS is best summarized in A TOPSIS Based Robust Optimization Methodology for Multivariable Quality Characteristics. ${ }^{58}$

The purported advantage of TOPSIS over AHP is that it can find the "best" alternative quickly, from an operational (i.e., end-to-end application) perspective. ${ }^{59}$ However, it has been quantitatively suggested through a detailed comparison of AHP and TOPSIS conducted by Zanakis, that TOPSIS is less accurate than AHP in determining the best-ranked alternative from a set of alternatives as well as a poorer matching to an assumed correct ranked order of alternatives than AHP. ${ }^{60}$ With regard, to the previously mentioned VCDMs, TOPSIS is identical to MAUT in its output, namely a ranked ordering of alternatives, and AHP is similar to NPV and CBA in its mapping alternatives to a cardinal scale, albeit not a monetary one necessarily. However, it should be noted that AHP and TOPSIS both rely on an ad hoc assignment of importance weights to attributes (or decision nodes in the case of AHP), which clearly prohibits these weighting functions from embodying a set preference structure for decision makers, regardless of where the structure is derived from. Consequently, AHP and TOPSIS violate the basic von Neumann and Morgenstern axiomatic structure of normative utility theory. ${ }^{4}$

13

American Institute of Aeronautics and Astronautics 
In the case of TOPSIS, some of the earliest research supporting TOPSIS concluded an inability of the method to embed human behavior in the TOPSIS distance functions and that regardless, it suffers from the mutual additive (preferential) independence as do value, NPV, and CBA functions, motivating the use of MAUT in place of TOPSIS. ${ }^{61}$ While inherent advantages of TOPSIS such as providing a "clear and easily understandable geometric meaning" are often stated in literature, they are also often unsubstantiated beyond the statements made. ${ }^{62}$ Furthermore, there has yet to be a publication pertaining to TOPSIS justifying the method in the field of economics and psychology (or some other field) as an acceptable (normative or descriptive) theory of decision making under certainty or uncertainty. In fact, the opposite has occurred with one of the more recent publications applying TOPSIS further violating the tenets of social choice, only distancing TOPSIS from having a substantiated academic foundation. ${ }^{63}$ Regardless, TOPSIS still has an appreciable user base knowingly or unknowingly aware of the inherent limitations of this alternative rank-ordering method, and it is indeed a rapid method to employ for consistent decision-making.

Conversely, in the case of AHP, there is still an on-going and complex debate as to the validity of AHP relative to the tenets of economic theory; however, the debate is likely to continue. ${ }^{64}$ Conceptually, advocates of AHP have not proved the conformance of AHP to the basic von Neumann and Morgenstern axiomatic structure of normative utility theory and instead justified AHP on the basis that such conformance is not required for a decision-making method. Opponents of AHP, who are most often instead in support of MAUT, continue to argue that AHP is fundamentally unsound. Ultimately, regardless of these arguments, AHP methods' derivation of value can become very complex and consequently loose transparency, which makes the method akin to a "black box" model where inputs lead to outputs but the transition of inputs to outputs is difficult, or impossible to understand. The consequence of this is that AHP cannot be a useful consensus building tool if the mapping of inputs to outputs cannot be easily understood, visualized, and hence actively adapted per the desires of decision-makers (stakeholders). ${ }^{65}$

\section{E. The VCDM Assumptions}

The notable differences between the aforementioned VCDMs are their respective (1) conformance to the actual decision-making behavior of stakeholders (i.e., the independence assumption); (2) ability, or lack thereof, to aggregate multiple sources of value/benefit/cost; and (3) monetization, or lack thereof, of the source(s) of value/benefit/cost. It is thus necessary to consider these and other assumption-based differences in choosing the "best" VCDM to employ as some VCDMs require far more unsubstantiated (liberal) assumptions than others, and this has direct ramifications the VCDM valuation accuracy and conformance to stakeholder-perceived value, for a given system.

The intent of enumerating the various VCDM options is not to prescribe a given VCDM, but rather, place each of the VCDMs in context with the others. Subsequently, this serves as the most appropriate basis for comparing the most prominent VCDMs. To this end, Table 1 provides a succinct listing of the VCDM assumptions cited herein as a means for logically structuring an argument for, and against, the use of any of these VCDMs on the basis of their inherent assumptions, and hence the VCDM developer's/user's comfort in making these assumptions. It needs to be recognized that the comprise in appropriateness and accuracy in selecting the most "valuable" outcome (system) via the VCDM because of its assumptions is bestowed to the decision-maker's (stakeholder's) for that outcome (system), as they ultimately reap the benefits for making the correct decision but pay the price for having made the incorrect one.

The motivation for summarizing the major assumptions in each of the VCDMs in Table 1 is to allow a potential user to select the best VCDM on the basis of minimizing the number of assumptions they are comfortable with making and the number of assumptions they disagree with. To perform this activity, read Table 1 row-by-row, starting at the top of Table 1. Place an "X" or tally mark in each column of a given row that you disagree with or are not comfortable making that assumption. Then move onto the next row. In a given row, assumptions that are identical are called out by being shaded in gray, hence an $\mathrm{X}$ in one column corresponding to an assumption shaded in gray requires an $\mathrm{X}$ in the tally columns corresponding to all other assumptions shaded in gray. After reviewing all the rows, take the summation of all "X's" or tally marks in each column. The VCDM that is potentially the best for you, based on minimizing the number of assumptions you are uncomfortable making is the column and corresponding VCDM with the least number of tally marks, on an absolute scale. While it is recognized that there are other driving criterion (e.g., political pressure) for selecting the best VCDM for a particular application, this paper purports that the assumptions and ensuing inaccuracies of quantifying value are the most important criterion for selecting a VCDM. 
Table 1. Using assumptions as guidance for selecting the most suitable VCDM.

\begin{tabular}{|c|c|c|c|c|c|c|}
\hline & & $\overline{\mathbf{A}}$ & & B & & $\mathbf{C}$ \\
\hline $\begin{array}{l}\text { Definition } \\
\text { of Value }\end{array}$ & Value is discounted cash flow (monetized) & & Value is discounted cash flow (monetized) & & $\begin{array}{l}\text { Value is an aggregation of a set of benefits } \\
\text { relative to their respective net cost (non- } \\
\text { monetized) }\end{array}$ & \\
\hline $\begin{array}{l}\text { Sources of } \\
\text { Value }\end{array}$ & $\begin{array}{l}\text { Value is not derived from any sources other } \\
\text { than revenue }\end{array}$ & & $\begin{array}{l}\text { Value is derived from multiple benefits and } \\
\text { costs }\end{array}$ & & $\begin{array}{l}\begin{array}{l}\text { Value is derived from multiple benefits and } \\
\text { costs }\end{array} \\
\end{array}$ & \\
\hline \multirow[b]{2}{*}{$\begin{array}{l}\text { Market } \\
\text { Prediction }\end{array}$} & Cash flow and discount rate & & Cash flow and discount rate & & & \\
\hline & $\begin{array}{l}\text { Extensive and quantitative predictions can be } \\
\text { made about a system's future financial } \\
\text { markets, revenue and pricing structures, } \\
\text { demand functions, etc. }\end{array}$ & & $\begin{array}{c}\text { Extensive and quantitative predictions can be } \\
\text { made about a system's future financial } \\
\text { markets, revenue and pricing structures, } \\
\text { demand functions, etc. }\end{array}$ & & & \\
\hline \multirow[t]{2}{*}{$\begin{array}{l}\text { Psycho- } \\
\text { Economic }\end{array}$} & $\begin{array}{l}\text { Mutual additive (preferential) independence- } \\
\text { stakeholder(s) desirability for one system } \\
\text { attribute value is entirely independent of the } \\
\text { respective values of all other system attributes }\end{array}$ & & $\begin{array}{l}\text { Mutual additive (preferential) independence- } \\
\text { stakeholder(s) absolute preference for a given } \\
\text { attribute is independent of the respective } \\
\text { values of all other system attributes }\end{array}$ & & $\begin{array}{l}\text { Mutual utility independence }- \text { stakeholder(s) } \\
\text { relative preference between two values for a } \\
\text { given attribute is independent of the respective } \\
\text { values of all other attributes; absolute } \\
\text { preference for one attribute is dependent on } \\
\text { the respective values of all other attributes }\end{array}$ & \\
\hline & $\begin{array}{l}\text { Stationary assumption - stakeholder } \\
\text { preferences do not change over time }\end{array}$ & & $\begin{array}{l}\text { Stationary assumption - stakeholder } \\
\text { preferences do not change over time }\end{array}$ & & $\begin{array}{l}\text { Stationary assumption - stakeholder } \\
\text { preferences do not change over time }\end{array}$ & \\
\hline \multirow[b]{2}{*}{$\begin{array}{l}\text { Stakeholder } \\
\text { Perception }\end{array}$} & $\begin{array}{l}\text { Multiple stakeholder preferences cannot be } \\
\text { aggregated - nonexistence of a social welfare } \\
\text { function }\end{array}$ & & $\begin{array}{l}\text { Multiple stakeholder preferences cannot be } \\
\text { aggregated - nonexistence of a social welfare } \\
\text { function }\end{array}$ & & $\begin{array}{l}\text { Multiple stakeholder preferences cannot be } \\
\text { aggregated - nonexistence of a social welfare } \\
\text { function }\end{array}$ & \\
\hline & $\begin{array}{l}\text { Stakeholder's make decision's under certainty } \\
\text { - they have perfect foresight into all present } \\
\text { and future events pertaining to the values of a } \\
\text { system's attributes }\end{array}$ & & $\begin{array}{l}\text { Stakeholder's make decision's under certainty } \\
\text { - they have perfect foresight into all present } \\
\text { and future events pertaining to the values of a } \\
\text { system's attributes }\end{array}$ & & $\begin{array}{c}\text { Stakeholders make decisions under } \\
\text { uncertainty - they do not have perfect insight } \\
\text { into all present and future events pertaining to } \\
\text { the values of a system's attributes }\end{array}$ & \\
\hline \multirow{5}{*}{$\begin{array}{l}\text { Calculating } \\
\quad \text { Value }\end{array}$} & $\begin{array}{l}\text { Cash flow and/or discount rate are discrete in } \\
\text { time and also potentially held as constants }\end{array}$ & & $\begin{array}{l}\text { Monetized benefits, costs, and/or discount rate } \\
\text { are discrete in time and also potentially held as } \\
\text { constants }\end{array}$ & & & \\
\hline & & & Monetization of benefit(s) & & & \\
\hline & & & $\begin{array}{l}\text { Combine and normalize multiple benefits and } \\
\text { costs into a single metric }\end{array}$ & & & \\
\hline & $\begin{array}{l}\text { Truncation of information regarding } \\
\text { distribution of costs (monetized) }\end{array}$ & & $\begin{array}{c}\text { Truncation of the distribution of costs and } \\
\text { benefits (monetized) }\end{array}$ & & $\begin{array}{l}\text { Truncation of the distribution of benefits into } \\
\text { a single metric }\end{array}$ & \\
\hline & Value is a cardinal metric & & Value is a cardinal metric & & $\begin{array}{l}\text { Ordered comparison of benefit (non-ratio } \\
\text { cardinal) and cost (cardinal) is assumed a } \\
\text { proxy for value }\end{array}$ & \\
\hline Tally & Total Disagreements & & Total Disagreements & & $\begin{array}{l}\text { Total Disagreements } \\
\end{array}$ & \\
\hline VCDM & $\begin{array}{l}\text { Net Present Value } \\
\text { (NPV) }\end{array}$ & & $\begin{array}{l}\text { Cost-Benefit Analysis } \\
\text { (CBA) }\end{array}$ & & Multiple Attribute Utility Theory (MAUT) & \\
\hline
\end{tabular}




\section{V. "Valuing" Systems: An Illustrative Demonstration}

An analysis pertaining to the valuation of spacecraft is employed to compare the aforementioned prominent value-centric design methodologies (VCDMs): NPV, MAUT, and CBA. The objective of the analysis is not to provide an absolute measure of a spacecraft's value but rather to illustrate the potential, and meaningful differences in recommendations put forth through the quantification of "value" by these three VCDMs. In doing this, it emphasizes the sensitivity of a system's purported "value" to the VCDM used to quantify that value and thereby the sensitivity of recommendations formulated about that system based on its value quantification from a given VCDM and its implicit assumptions. Therefore, the analysis is useful for holistically coupling the core concepts in this paper, and through it, much can be learned about the advantages, disadvantages, and assumptions of today's most prominent approaches (i.e., VCDMs) for value-driven system design.

\section{A. Spacecraft}

\section{Missions}

The analysis considers spacecraft performing one of two missions. The first mission is a telecommunications mission where the spacecraft have the objective of serving as a space-based platform to assist in receiving and transmitting signals (e.g., information feeds), which originate from ground-based transmission sources. Conversely, the second mission considered in the analysis is a deep-space observation mission where the spacecraft have the objective of observing phenomenon in deep (i.e., extragalactic) space and subsequently collecting valuable information for the broader scientific community. The spacecraft performing the telecommunications mission hold a geostationary earth orbit assume an orbit altitude and inclination of $35,786 \mathrm{~km}$ and $0.0^{\circ}$, respectively. And, the spacecraft performing the deep space observation mission assume an orbit profile akin to that of Hubble Space Telescope, namely, a circular orbit with an altitude and inclination of $593 \mathrm{~km}$ and $28.5^{\circ}$, respectively. Note, the spacecraft performing both missions are assumed to operate alone rather than as part of a constellation of multiple spacecraft.

The purpose of selecting these two missions is that they offer nearly fundamentally distinct perspectives on the perceived value of the system (spacecraft). The telecommunications mission provides a direct (known) service (i.e., value) to its respective customers and hence has a market demand, which can be measured and priced accordingly. In contrast, the deep-space observation mission provides value to a broad (and not fully known) community, which in turn is not directly paying for the "service" (i.e., value) provided by the system. The intent of using these two missions in the analysis is thus to demonstrate the inherent advantages and disadvantages of prominent VCDMs when the system under consideration has an obvious (and measurable) value source, in dollar terms, and also when the system under consideration provides value to its users incommensurable with dollars.. It is thereby assumed that these two missions provide a reasonably holistic case for illustrating the application of, and subsequent recommendations formulated through, prominent VCDMs.

\section{Spacecraft and Mission Payloads}

The analysis specifically considers monolithic spacecraft designs, each of which has the following subsystems: tracking, telemetry, and control; attitude control; guidance control; propulsion; thermal control; structures and wiring; communications; computer system and command \& data handling; tracking, telemetry, and control; attitude determination; guidance navigation; and electrical power generation and storage. In terms of specific subsystem hardware, it is relevant to note that the power generation relies on solar arrays and the attitude and guidance control actuators consist of a coupled three-axis reaction wheel unit and monopropellant, liquid propulsion system. Also worth noting is that these spacecraft employ technically mature, space qualified subsystem technologies as the emphasis is on spacecraft reliability, not innovation.

In addition to these standard bus (supporting) subsystems, the telecommunications spacecraft have two high-gain directional antennas for dedicated uplink and downlink transmission and a variable number and combination of L, S, $\mathrm{C}, \mathrm{K}_{\mathrm{u}}, \mathrm{K}_{\mathrm{a}}$, or X-band transponders. These transponders are configured to meet the data rate and channel capacity demand for any grouping of standard definition (SD) channels, high-definition (HD) channels, and/or internet bandwidth. It is assumed that each directional antenna is parabolic and gimbaled to provide appropriate coverage, given spacecraft pointing capability and slewing constraints. Each antenna also has a variable diameter sized to meet the user receive and transmit uplink and downlink data rate requirements, respectively.

In addition to the aforementioned standard bus subsystems, the deep-space observation spacecraft have one directional antenna that is predominantly dedicated to downlink, one omni-directional antenna that is exclusively dedicated to uplink, and an optical mirror (telescope) for capturing visible wavelength $(500 \mathrm{~nm})$ images of phenomenon in deep space. 
Given the attributes and the ranges of their corresponding independent design variables, a total of 315 and 192 spacecraft designs were considered as candidates for the telecommunications and deep-space observation mission, respectively.

\section{B. Value-Driven Design}

1. Value-Centric Design Methodologies

To assess the purported value of the spacecraft considered in the analysis, and thereby differences in the perception of the most "valuable" spacecraft considered for each mission, three VCDMs are employed: Net Present Value (NPV), Multiple Attribute Utility Theory (MAUT), and Cost-Benefit Analysis (CBA). As mentioned previously, these three VCDMs were selected due to their prominence in value-centric assessments of systems. In the domain of space systems, this is evidenced by research in academia and the Defense Advanced Research Projects Agency (DARPA) System F6 (Future, Fast, Flexible, Fractionated, Free-Flying) Program. 3,4,7,8,9,11,46,66

\section{Attributes}

For the purpose of this research, an attribute is a characteristic of a spacecraft (system) assumed to embody objectives of a system that are useful/desirable to the stakeholder(s) of interest and adhere to the five properties of an attribute set established by Keeney and Raiffa: complete, operational, decomposable, non-redundant, and minimal. ${ }^{18}$ For each of the spacecraft considered in the two missions, the metrics required to populate the value proposition differs between the VCDMs considered, but all are fundamentally based on the same respective attributes of the two missions; this is done to keep the comparison of value propositions as quantified by the different VCDMs uniform with respect to benefits and costs. For example, NPV formulates a value proposition in terms of a single, monetary metric whereas MAUT quantifies a value proposition in terms of the ordered pair of MAU and lifecycle cost, but both value propositions are derived from an identical set of attributes (benefits).

The respective attributes for both missions were derived assuming a pseudo, governing stakeholder for both missions. Hereafter, the stakeholder for each mission is given as well as their respective value proposition (objective) for that mission, from which the attributes for each mission shown in Table 2 were selected. The attributes corresponding to each mission are the intrinsic (and often emergent) benefits provided by spacecraft performing these missions per the stakeholder and their respective value proposition. Thus, these attributes along with the cost of the spacecraft need to be quantified per the specific VCDM employed to ultimately quantify the value proposition.

Telecommunications Mission

- Stakeholder: Satellite Owner and Service Provider (e.g., DirecTV®, Inc.)

- Value: Provide high quality broadband entertainment to subscribers in North America for at least five years using one satellite, while maximizing profit.

Deep-Space Observation Mission

- Stakeholder: Civil Science Agency (e.g., NASA)

- Value Proposition: Provide visible wavelength images of astrophysical phenomenon, in particular stellar phenomenon, in deep space (i.e., extragalactic) for support of scientific studies for at least five years.

Table 2. Attributes (benefits) for the telecommunications and deep-space observation missions. Telecommunications Mission

Deep-Space Observation Mission

\begin{tabular}{|c|c|c|c|c|c|c|c|c|c|}
\hline \multicolumn{2}{|r|}{ Attribute } & \multirow{2}{*}{\begin{tabular}{|l|}
\multicolumn{1}{|c}{ Definition } \\
$\begin{array}{l}\text { Operational duration of } \\
\text { spacecraft }\end{array}$ \\
\end{tabular}} & \multirow{2}{*}{$\begin{array}{l}\text { Units } \\
\text { years }\end{array}$} & \multirow{2}{*}{$\begin{array}{c}\begin{array}{c}\text { Range (least to } \\
\text { most desirable) }\end{array} \\
{[5,15]} \\
\end{array}$} & \multicolumn{2}{|r|}{ Attribute } & \multirow{2}{*}{\begin{tabular}{|l|}
\multicolumn{1}{|c}{ Definition } \\
$\begin{array}{l}\text { Operational duration of } \\
\text { spacecraft }\end{array}$ \\
\end{tabular}} & \multirow{2}{*}{$\begin{array}{c}\text { Units } \\
\text { years }\end{array}$} & \multirow{2}{*}{$\begin{array}{r}\begin{array}{r}\text { Range (least to } \\
\text { most desirable) }\end{array} \\
{[5,15]}\end{array}$} \\
\hline 1 & Mission Lifetime & & & & 1 & Mission Lifetime & & & \\
\hline 2 & \begin{tabular}{|l|} 
Max Number of High \\
Definition Channels
\end{tabular} & $\begin{array}{l}\text { Max number of distinct HD } \\
\text { channels available for broadcast }\end{array}$ & - & {$[0,100]$} & 2 & Payload Pointing Stability & $\begin{array}{l}\text { Level of pointing accuracy about } \\
\text { dominant spacecraft inertia axis }\end{array}$ & $\mathrm{rd}$ & [1e-01, 1e-06] \\
\hline 3 & $\begin{array}{l}\text { Max Number of Standard } \\
\text { Definition Channels }\end{array}$ & $\begin{array}{l}\text { Max number of distinct SD } \\
\text { channels available for broadcast }\end{array}$ & - & {$[0,200]$} & 3 & Angular Resolution & $\begin{array}{l}\text { Min. angular separation of two } \\
\text { points that can be differentiated }\end{array}$ & mas & {$[1000,1]$} \\
\hline 4 & $\begin{array}{l}\text { Max Downlink Internet } \\
\text { Bandwidth }\end{array}$ & $\begin{array}{l}\text { Max downlink internet } \\
\text { bandwidth (aggregate) }\end{array}$ & Mbps & {$[0,1080]$} & 4 & Slew Rate & $\begin{array}{l}\text { Rate of rotation about dominant } \\
\text { spacecraft inertia axis }\end{array}$ & $\mathrm{rd} / \mathrm{s}$ & {$[2 \mathrm{e}-06,1 \mathrm{e}-01]$} \\
\hline 5 & $\begin{array}{l}\text { Uplink Internet } \\
\text { Bandwidth }\end{array}$ & $\begin{array}{l}\text { Max uplink internet bandwidth } \\
\text { (aggregate) }\end{array}$ & Mbps & {$[0,1080]$} & 5 & Focal Ratio & $\begin{array}{l}\text { Aperture focal length relative to } \\
\text { its major axis diameter }\end{array}$ & - & {$[\mathrm{f} / 40, \mathrm{f} / 1]^{*}$} \\
\hline
\end{tabular}

In examining the results of the analysis in the ensuing sections, it is important to recognize the assumptions made by each VCDM in their quantification of the value proposition as well as the recommendations a decision-maker may formulate based on the value represented by the VCDM results.

\section{Assessment: The Spacecraft Evaluation Tool}

The spacecraft performing the telecommunications and deep-space observation missions were assessed using the Spacecraft Evaluation Tool (SET). The SET is a high-fidelity spacecraft modeling tool with the capability to model 
monolithic or fractionated spacecraft designs having either earth imaging, telecommunications, or deep-space observation mission payloads; the latter two payloads were incorporated into the SET specifically for this research. The SET has been developed over the course of three years and consists of both a physics-based and cost model. Further documentation pertaining to the SET capability, verification, and its respective three functional divisions (inputs, algorithms, and outputs) can be found in other documentation. ${ }^{24,67,68}$

1. Lifecycle Cost

Given the broad interpretation of lifecycle cost metrics, it is important to note the constituents of the lifecycle cost for a given monolithic spacecraft considered in this analysis. The lifecycle cost constituents, the sum of which yield the lifecycle cost, include both nonrecurring (NRE) and recurring (RE, aka T1) costs for a spacecraft. The NRE costs include the cost of designing, developing, manufacturing, integrating, testing, assembling, and launching a spacecraft. The RE costs include the cost of operations support, human labor, and ground station facilities. Note that the lifecycle cost of a given spacecraft represents the cost of a deterministic lifecycle, that is, there are no launch vehicle or spacecraft on-orbit failures during the lifecycle. Also, given the use of parametric cost estimating relationships in quantifying the lifecycle cost for a given spacecraft, there is uncertainty associated with the lifecycle cost output by the SET, however, this is not treated herein for ease of presenting the analysis results. ${ }^{24}$

\section{Quantification of Attributes}

The SET is used to quantify the attributes for a given spacecraft, however, given the input structure of the SET, some of the attributes, in particular for the deep-space mission, are not emergent properties of the system; these include the attributes of pointing-axis stability and mission lifetime. However, other than these attributes, the attributes are emergent benefits of a spacecraft where their respective values cannot be known with certainty given the SET of inputs. The nature of the attribute quantification is necessary to mention because it implies that spacecraft benefits (and costs) cannot be simply derived from inputs known a priori to designing a spacecraft, which in turn justifies the need to select the "best" or most "valuable" spacecraft design through an exploration of design alternatives. And in the case of this research, design alternatives are filtered through VCDMs, the operational manifestation of this research.

\section{Results: Telecommunications Mission}

The results from the telecommunications mission demonstrate the applicability of the aforementioned VCDMs for informing value-driven design. For this particular mission, given the market viability of telecommunications satellites, all three VCDMs, that is, NPV, MAUT, and CBA were successful in their valuation of candidate satellite designs, given their respective limitations (assumptions). Since each of the attributes for the telecommunications mission directly contributes to revenue, NPV and CBA converge in their respective analysis and results, hence, they are considered the same for this study. Note this would not be the case had any of the attributes not directly contributed revenue, for example, if one of the attributes was a proxy for system "flexibility" to changing demand. The results from this application of VCDMs, as detailed hereafter, enumerate one of the focal objectives of this paper, namely, decisions based on the "value" of a system are extremely volatile to the interpretation of value per the VCDM used. As will be demonstrated, the prescription as to the most "valuable" design(s) varies appreciably between the recommendations made by NPV/CBA and MAUT, which highlights a notable learning, namely, that consensus is not reached by these two differing philosophies of value.

\section{Net Present Value and Cost-Benefit Analysis}

The NPV/CB analysis quantified the value of the 315 spacecraft designs considered in the telecommunications study, specifically by monetizing attributes $2-5$ in Table 2 for the telecommunications mission relative to the mission lifetime (Attribute 1 in Table 2), given that these attributes are time dependent. The monetization required assumptions regarding a stakeholder's willingness to pay for the high definition channel, standard definition channel, and internet service. The data used to determine the willingness to pay for each of these respective services was taken directly from commercial providers of these services with the assumption that their respective pricing structures are indicative of the United States' current market supply and demand for these services, a reasonable assumption.$^{69}{ }^{70}$ The cost-time profile, the other information needed for a NPV and CBA value quantification, is directly output from the SET. A discount rate of $10 \%$ was assumed, a standard starting value for discounted cash flow analyses of space systems. ${ }^{71}$ Based on this information, each spacecraft design investigated produced a cash flow (i.e., revenue minus cost) and corresponding discounted cash flow profile akin to the one shown in Fig. 1. As observed in Fig. 1, the five-year development of the spacecraft yields no revenue and the time spreading of costs is reflective of beta-type distribution of costs where the outlier cost "spikes" correspond to launch vehicle procurement (insurance) payments. Once the operation of the spacecraft begins, revenue is realized and the cash flow and discounted cash flow become positive quantities; note a constant (flat) demand curve was assumed. 
The results from the NPV/CB analysis are shown in Fig. 2. Given the assumed stakeholder for the telecommunications mission, the operational costs for a satellite and its respective revenue, as aggregated in Fig. 2, is consistent with public investor information provided by DirecTV, Inc. ${ }^{72}$ A trend worth noting in Fig. 2 is the clusters of design, these correspond to the seven mission lifetime values considered, where a longer mission lifetime corresponds to a cluster further to the right in Fig. 2 with respect to the $x$-axis. In each cluster, many of the designs provides appreciable revenue and thus has a positive NPV/CB, however, some have a negative NPV/CB because their allocation of transponders to standard definition channels and internet (instead of high definition channels) does not offset the cost of developing and operating the spacecraft over the lifetime. From the

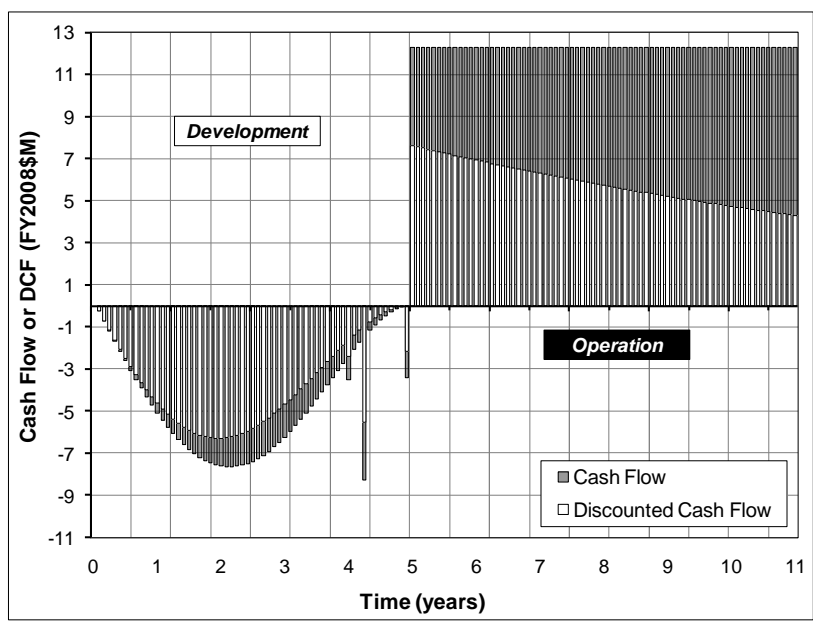

Figure 1. NPV/CBA, representative monetary profiles.

NPV/CB analysis results, the recommendation as to the most "valuable" design is one that has the longest mission lifetime (i.e., 12 years) and that allocates all transponders to the relay of high definition channels. This result is intuitive given the present marketing of high definition television and the associated higher pricing structure per channel for such services than for standard definition television and mobile broadband (internet).

\section{Multiple Attribute Utility Theory}

The MAUT analysis was successfully applied based on the five attributes for the telecommunications mission shown in Table 2. The results from this analysis are shown in Fig. 3. As observed from the MAU-lifecycle cost ordered pairs in Fig. 3, there is a positive correlation between MAU and lifecycle cost, thus supporting the common notion that more benefit can be had for more cost. From the results shown in Fig. 3, the notable trades are those designs with the highest benefit for a given lifecycle cost value; these comprise the Pareto Set also shown in Fig. 3. Subsequently, these designs are purported to provide the most desirable attribute values relative to the

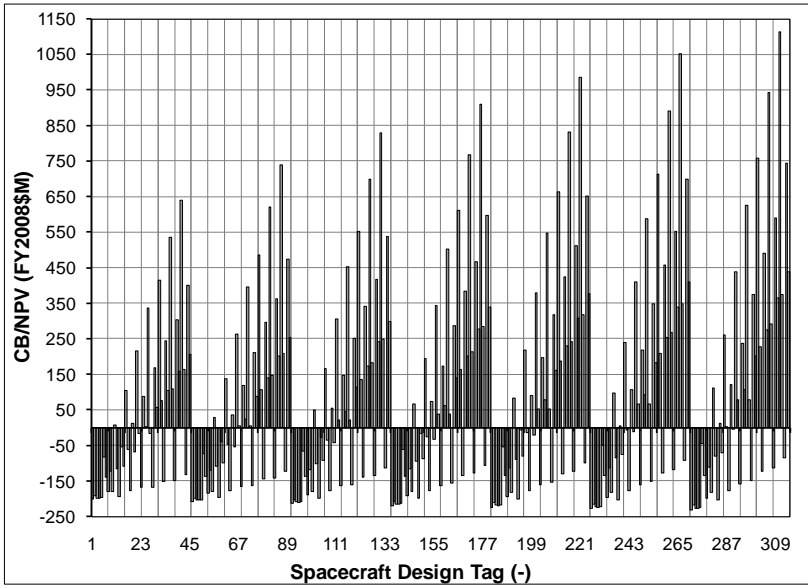

Figure 2. NPV/CBA, results.

associated costs of this provision. In particular, given the preference structure used in the MAUT analysis, these Pareto set designs maximize the aggregate benefit relative to cost by allocating all the transponders to the relay of standard definition channels. From a purely benefit-maximization and cost-minimization standpoint, this conclusion makes sense because for a given number of transponders (and thus aggregate data rate capability), one can obtain the most benefit per unit spacecraft cost through relaying standard definition channels, which have an appreciably smaller data rate requirement than high definition channels. Moreover, this observed trend is the case because television channels (SD or HD) provide more benefit than mobile broadband given the preference structure set forth for the MAUT analysis, assuming that there is a more inelastic market for television than for mobile broadband (see Appendix). This assumption is consistent with any first-order measurement of the number of individuals having household cable and not mobile (direct satellite) broadband, although given the increasing prevalence of internet capable phones and households this trend is changing.

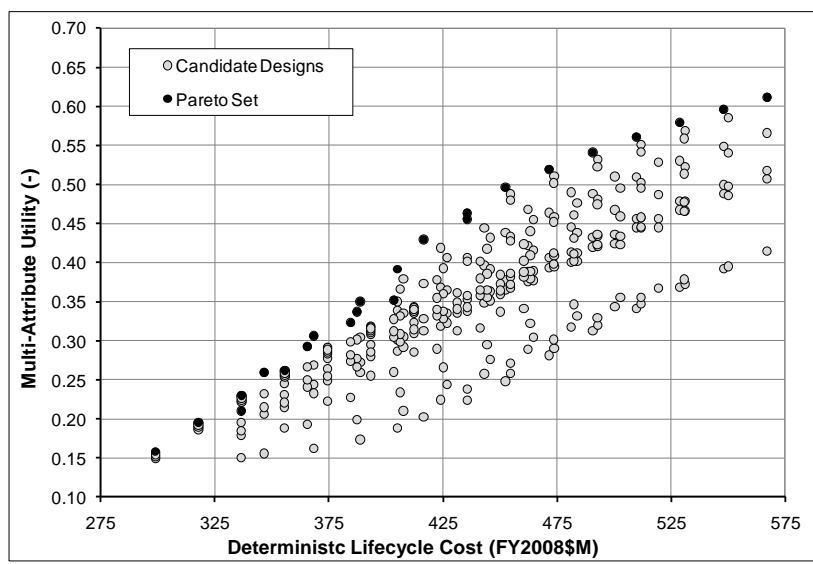

Figure 3. MAU-lifecycle cost solution space. 
AIAA Space 2010

Sept. 2010, Anaheim, CA

Revision 10/06/2010

\section{Recommendations}

The recommendation as to the most "valuable" spacecraft design from NPV, MAUT, and CBA differs significantly. A summary of these recommendations is shown the MAU - lifecycle cost space in Fig. 4. CBA and NPV immediately siphon the generalized cost-benefit space down to one design, which is certainly convenient, not leaving the selection of the most valuable design subject to interpretation. However, MAUT leaves more of the tradespace open, suggesting that 23 designs are the most valuable while not precluding other trades to be considered (e.g., more value may be had by selecting a less beneficial spacecraft that costs slightly less). Thus, for this telecommunications mission, the MAUT approach facilitates constructive discussion (decision-making) because it keeps the spacecraft design in a cost-benefit tradespace whereas NPV and CBA do not, and this may (or may not) be desirable to stakeholder's of the system.

The two recommendations from these three methods are in fact mutually exclusive - NPV/CBA (supply only HD channels, which are the most revenue maximizing usage of a given transponder) and MAUT (supply only SD channels, which are the most benefit maximizing and cost minimizing usage of a given transponder). The disparity in the two recommendations from these three VCDMs assuredly provides one instantiation of no convergence in value-driven design philosophies and ensuing ability to confidently select the most "valuable" design for the mission. Ultimately, from a value-driven (informed) design standpoint, this conclusion is entirely worrisome as there is no clear agreement amongst the respective value of the 315 spacecraft considered when using today's more prominent value-centric design methodologies. Further exacerbating the disagreement in recommendations is that to the first order of "valuing" systems, the recommendations derived from NPV/CBA and MAUT demonstrate significant variance, but this ignores the potentially high variance in value quantifications when using a given VCDM, based on its assumptions.

Lastly, on the discussion thread of differing value philosophies, implicit to each VCDM application is their respective assumptions, as summarized in Table 1. Thus, the recommendations from NPV/CBA and MAUT need to be positioned with respect to these assumptions. For example, while NPV/CBA suggests a long-lived spacecraft supplying only HD television channels is the most valuable; this was derived assuming that people's willingness to pay for HD channels is independent of SD channels and internet, a liberal assumption and something that MAUT does not assume in its derivation of value. Thus, it is suggested that the respective value propositions from the telecommunications investigation summarized in Fig. 4 be examined with observance to their respective assumptions and not simply as point "values."

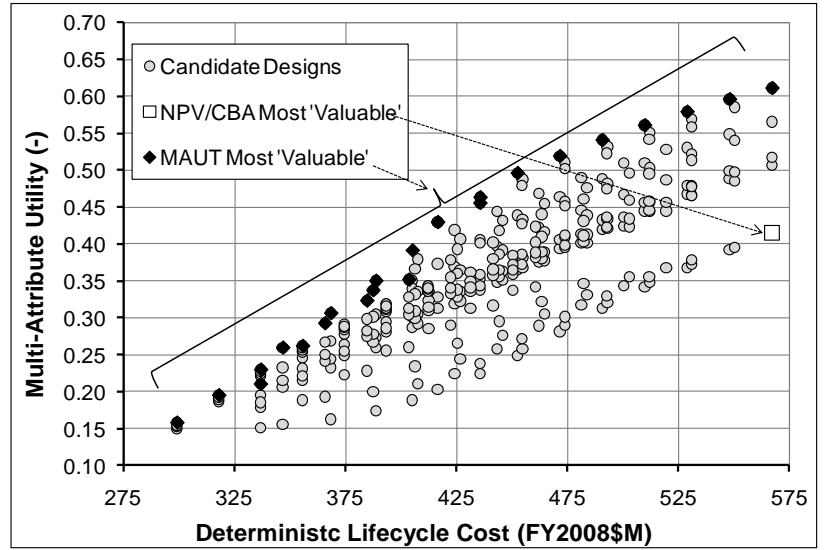

Figure 4. Comparison of most "valuable" designs.

\section{E. Results: Deep-Space Observation Mission}

The results for the deep-space observation mission demonstrate the limitations of VCDMs (i.e., NPV and CBA) relying on a person's willingness to pay for attributes of a system that are never justified as providing a direct monetary benefit, such as those attributes shown for deep-space observation spacecraft in Table 2. In contrast, MAUT could be readily applied to "value" the deep-space observation mission, thereby informing the value-driven design of spacecraft designs for this mission. While conducting interviews to ascertain a stakeholder's willingness to pay for each of the deep-space mission attributes is possible, the authors purposefully avoided doing so after realizing the intractability of doing so. To this end, nothing has been demonstrated in literature sharing how the monetization of attributes for deep-space missions can be performed, a revealing situation that either implies that such a monetization is not well substantiated, or perhaps a source of competitive advantage. This conclusion that NPV and CBA are unsuitable for valuing the deep-space observation mission, coupled with publications stating the need for multi-objective (benefit) frameworks such as AHP and MAUT when dealing with non-monetary benefits, is a clear indication of either an inability to quantify the monetary value of certain technical attributes, or more likely, an inappropriateness of doing so. ${ }^{73,74}$ 
Fully supporting this decision are historical acquisition programs for these types of "general science" spacecraft (historically speaking) being justified on the basis of a scientific and not a monetary return philosophy. Consider the case of the Hubble Space Telescope where monetary benefits and revenue have not formed the argument for originally acquiring or servicing the spacecraft. ${ }^{75,76}$ This acquisition philosophy is well supported in literature on such "general science" space missions concluding that these missions do not generate appreciable revenue (if any) to offset their respective costs. ${ }^{73}$ Thus, studies justifying these systems have assumed value to be either derived from real options (benefits) such as serviceability and flexibility or from benefit proxies (abstractions) such as the number of academic publications citing the data generated from the system, discovery efficiency, and productivity - but never monetary return. ${ }^{73,77,78}$ Although, it has been suggested that revenue streams can be created for these types of spacecraft through rental and leasing scheme, this is a conceptual notion, not a viable market.

\section{Net Present Value and Cost-Benefit Analysis}

Given the aforementioned discussion, the valuation of candidate spacecraft designs for the deep-space observation mission is left to an algorithm in Table 3, for those wishing to make the required assumptions and conduct the required willingness to pay interviews. stakeholder's willingness to pay for each of the deepspace attributes in Table 2 such as pointing stability as well as a revenue (market demand and pricing) function for such a spacecraft given the pseudo deepspace observation stakeholder's value proposition. This algorithm is offered in place of a NPV and CB analysis, which requires potentially erroneous assumptions to be made, as supported by the previously cited literature, and lack thereof for the monetization of these (and other) technical system attributes through willingness to pay arguments. It should be noted that for NPV, the willingness to pay would only need to be ascertained for those attributes of the deep-space mission generating revenue whereas for CBA, all attributes would need to be considered. Therefore, in the case of NPV, it may likely be difficult to justify that any of the attributes lead to revenue in the first place and thereby demonstrate the inapplicability of this discounted monetization VCDM as compared to CBA.

\section{Multiple Attribute Utility Theory}

For the MAUT analysis, the relative preference structure is as manifested in single attribute utility functions is provided in Appendix B. This preference structure for the MAUT analysis assumes a stakeholder generally conservative (cautious) in their decision-making with respect to attaining more system benefit for more system cost. Hence, this stakeholder is risk-averse, which is indicative of a stakeholder's who has a tendency to prefer a certain outcome (payoff) to an uncertain but potentially more desirable outcome. The results from the MAUT assessment are presented in Fig. 5 and Fig. 6, the former presenting the ordered pairs of MAU and lifecycle cost and the latter providing the one-dimensional solution space where lifecycle cost is included as an attribute. The distinct clusters of four candidate designs in Fig. 5 showing an increase in MAU at a given cost is due to
Table 3. NPV and CBA algorithms.

\begin{tabular}{|c|c|}
\hline & Present Value \\
\hline & Quantify the initial investment for the spacecraft $D_{o}$ \\
\hline & Quantify the discount rate (inflation and real) $r$ \\
\hline & $\begin{array}{l}\text { Quantify revenue (profit minus cost) generated over the } \\
\text { course of lifecycle as a function of time } D(t)\end{array}$ \\
\hline & Compute the NPV via Eq. (1) \\
\hline & t-Benefit Analysis \\
\hline & Quantify the discount rate (inflation and real) $r$ \\
\hline & Quantify the cost of the spacecraft in time $C(t)$ \\
\hline & $\begin{array}{l}\text { Repeat for all attributes } \\
\quad-\text { Quantify monetary value of attribute in time } v\left(x_{i}, t\right)=B(t)\end{array}$ \\
\hline & Compute the CB via Eq. (3) \\
\hline
\end{tabular}

In particular, these assumptions include ascertaining a

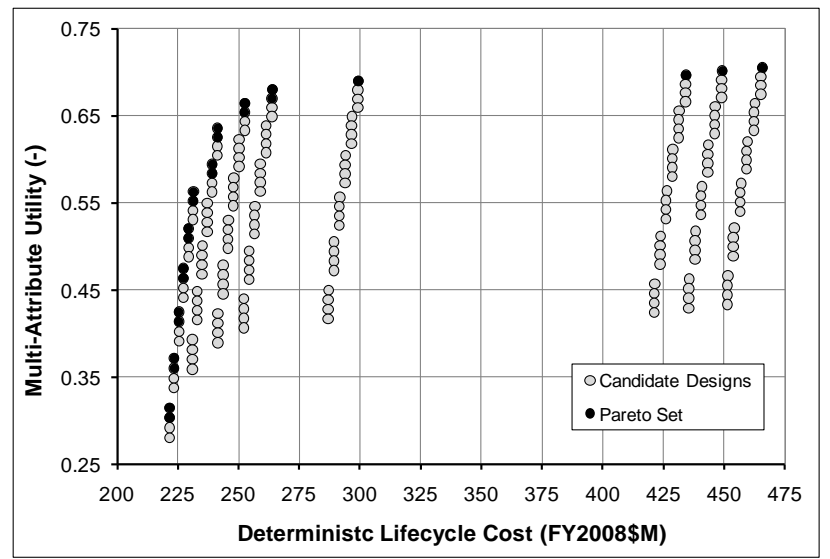

Figure 5. MAU, lifecycle cost solution space.

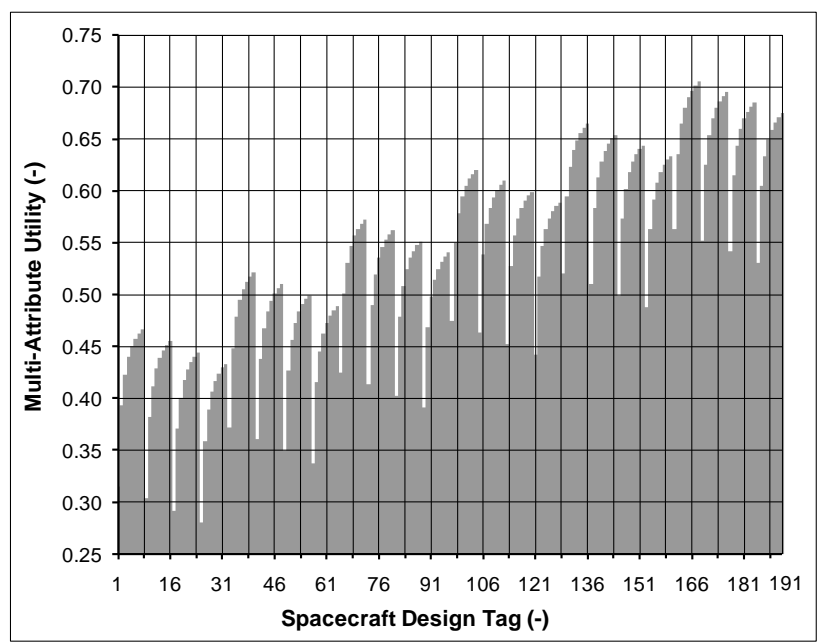

Figure 6. MAU solution space with lifecycle cost included as an attribute. 
an increasing (more accurate) pointing stability. And amongst the set of clusters of four designs, their movement vertically, that is providing more benefit at cost is predominantly due to an increasing mission lifetime, whereas their respective translation to the right (i.e., more cost) is predominantly due to a decrease in angular resolution. Thus, the two clear groupings of designs with regard to lifecycle cost from a change in launch vehicle usage.

In Fig. 6, the MAU values, where lifecycle cost is included as an attribute in addition to those shown in Table 2, are shown against the tag for the candidate design (there are 192 of them). The "jagged" clusters of designs, there are six of them, correspond to the six different mission lifetimes considered, and the higher the design tag, the higher its respective mission lifetime.

\section{Recommendations}

Given the purported inappropriateness of NPV and CBA in valuing deep-space observation spacecraft, as supported by the aforementioned cited literature, these methods offer no insight into the most valuable spacecraft designs considered for this mission. Conversely, MAUT is able to offer some insight as to the most valuable candidate spacecraft design for this mission. With respect to the MAU-lifecycle cost solution space shown in Fig. 5, those designs with the highest mission lifetime, lowest angular resolution, and highest focal ratios provide the most benefit, but do so for the highest cost; these are part of the Pareto Set represented by the black data points towards the top and right in Fig. 5. However, the other Pareto Set designs, towards the left in Fig. 5, are compelling alternatives because for a nearly equivalent mission lifetime and pointing accuracy, through having mediocre (slightly less than the best) focal ratios, angular resolutions, and slew rates, they have a lesser lifecycle cost. Conversely, if one considers the alternative MAUT analysis where lifecycle cost is included in the attribute set, the results of which are shown in Fig. 6, the most "valuable" design can be directly ascertained. Here value is internally computed as cardinal benefits relative to the associated cost of attaining these benefits via the MAUT governing equation. From this latter analysis, the most desirable spacecraft design for the deep-space observation mission has the following attribute values: mission lifetime (10 yrs), pointing stability (1e-06 rd), angular resolution (63 mas), slew rate $(8.5 \mathrm{e}-03 \mathrm{rd} / \mathrm{s})$, focal ratio (f/6.94), lifecycle cost (\$263.9M FY2008). Conceptually, this system is longlived, relative inexpensive as compared to other potential system designs because it has a reasonable, but not nearly the best, pointing-axis stability and angular resolution, and an appreciably low focal ratio implying that it has a large field-of-view.

\section{Discussion}

The intent of this paper is to introduce value-driven design in the context of differing perceptions of value, relative to well-vetted tenets and axioms of economics and psychology, as well as to substantiate the suitability of various methods for valuing systems, relative to assumptions, as illustrated by a case study. The discussion therefore synthesizes this body of work through a sequential summary of the: implications of the VCDM assumptions; case study used to demonstrate differing perceptions of value; a real-world example illustrating the one instantiation of a recent disconnect between philosophies of value perceptions in major United States aerospace companies; and the issue of aligning perspectives and methods for assessing value. In pursuing the discussion, it is relevant to reiterate that this paper does not seek to recommend how one should perceive system value, nor how one should operationalize value-driven design, but rather it seeks to provide a more comprehensive information basis that can be used to assess the current state of value-driven design in the aerospace industry.

\section{A. Informing Value-driven Design: Assumptions and Ensuing Insights}

Today's more prominent VCDMs offer a diverse set of methods for ascertaining the value of a system, but all contain inherent assumptions that must be recognized. This becomes an increasingly relevant task given the propensity to apply these methodologies with a focus on the results of the application, rather than on the assumptions inherent in these results; both are required for the appropriate application of a VCDM. Fundamentally, use of a VCDM implies the adoption of a valuation ideology wherein all assumptions and ensuing limitations of the VCDM must be accepted. In translating this notion to the valuation and selection of a system design, it would help to align perspectives by enumerating the inherent assumptions of a VCDM before presenting, discussing, and making recommendations based on the results from its application. This enumeration typically is not done in practice, as evidenced by the wealth of literature cited in this paper. It could be correctly argued that such incorporation of assumptions is essential in applying any methodology. However, what differentiates value from many other engineering measures of effectiveness used to assess a system is the inherently ambiguous and volatile nature of the term "value," in an engineering context. Most engineers are comfortable with value proxies such as mass, cost, and power, but once introduced to a term such as "value," this comfort tends to disappear. 
Ultimately, the perception of value, and resulting adoption of a value ideology, is at the crux of successfully using value to inform engineering design. This need to identify the value perception seems intuitive, but in practice may be difficult to achieve since there are often several different perceptions of value at work on the same system; for example, one from the stakeholder paying for a system, another from the developer and applier of a VCDM, and another from the program manager. Thus, selecting a unifying VCDM based on the acceptance of its respective assumptions and perhaps multitude of stakeholders is not a trivial task, and subsequently should be pursued with caution. The difficulty is only exacerbated given issues regarding the non-existence of a VCDM capable of aggregating multiple stakeholder preferences, without imposing compromises, as substantiated by Arrow's General Possibility Theory. ${ }^{42}$ The aforementioned reasoning, namely, the coupling of often numerous perceptions of value and the assumptions in each value ideology is the decisive catalyst in observed disconnects between the "value" of a system, as objectively determined by different individuals or organizations. An unsatisfying aspect in accepting this disconnect is that no one perception is wrong, but rather, all have strengths and weaknesses with respect to quantifying the value of a system under consideration.

Therefore, the issue of selecting the best VCDM, and thereby value ideology to adopt for a given valuation "problem," is non-trivial. The advantage of using a value-driven approach, regardless of the VCDM, is that new system design trades will be enumerated, which may not have been suggested through more traditional requirementand cost-centric trade study approaches. A risk, however, in employing a VCDM is that purported system value inherently reflects the assumptions implicit to that VCDM. It is not suggested that this is undesirable, but rather that there is an inherent risk in making recommendations as to the most valuable design per a particular VCDM, especially in the case where the stakeholders do not align well to the assumptions embodied in the recommendations. Thus, the suggestion for selecting the best VCDM for a particular application is ensuring acceptance and appropriate buy-in of the underlying assumptions, not for convenience, but in belief that (critical) decisions will be made on the basis of these assumptions.

\section{B. Informing Value-driven Design: The Telecommunications and Deep-Space Case Studies}

The two space missions, telecommunications and deep-space, were considered to demonstrate the applicability of three prominent VCDMs in the aerospace domain, namely, NPV, MAUT, and CBA. The two missions provide fundamentally distinct valuation contexts wherein the telecommunications mission has a viable market demand, and hence a pricing structure can be derived, whereas the deep-space mission does not. These two missions thereby served as a platform to demonstrate the applicability of the aforementioned VCDMs and, furthermore, the focal insight cited in the previous section that ultimately, a VCDM developer and user must respect the recommendations derived from applying a VCDM in the context of its respective assumptions.

For the telecommunications mission, NPV, CBA, and MAUT were all successful in "valuing" and thereby determining the most valuable design(s). However, interestingly the most valuable design recommended from NPV and CBA was not recommended as one of the most valuable designs using MAUT. And for the deep-space observation mission, MAUT was the only VCDM deemed capable of "valuing" the candidate spacecraft designs. In particular, this arose because conducting interviews to determine a stakeholder's willingness to pay for each of the deep-space mission attributes is possible, but perhaps inappropriate, especially since the stakeholders with preference on science attributes typically do not pay for the system. Additionally, the literature has yet to demonstrate how the monetization of such attributes can be performed in a reliable and fair manner, a situation that implies that such monetization is not well substantiated, or perhaps a source of competitive advantage.

While there are numerous insights pertaining to the case studies, in revisiting previous discussion points, perhaps the most important is the volatility of recommendations of the most valuable system per the perception of value. For example, holding stakeholder preference structure amongst the set of mission attributes constant, irrespective of a particular VCDM, the results from the telecommunications mission substantiate the potential to lose or gain a valuable opportunity depending on a stakeholder's adopted value ideology. Based on the results from the telecommunications mission, the NPV/CBA- and MAUT-recommended most valuable designs both have the same costs, however, the MAUT design has appreciably more benefit, per the stakeholder's preference for the mission attributes, than the NPV/CBA most valuable design, which in turn generates more revenue. Thus, for a stakeholder ignoring the MAUT valuation approach, they have indeed missed the opportunity to appreciably increase the value (mission attributes relative to cost) of the spacecraft design - at no additional cost to the NPV/CBA most valuable design. Conversely, for a stakeholder only ignoring the NPV/CBA approaches, they will not select the most valuable (profit maximizing) design, and thereby end up making, at a minimum, \$740M (FY2008) less profit than the NPV/CBA-recommended most valuable design. A different situation occurs in terms of the deep-space mission because there are no recommendations from NPV/CBA. Hence, MAUT shows itself the only method for informing value-drive design in this case. 
In particular, the results from the telecommunications mission motivate the potential to have significant variance in the "value" of the system, as quantified by different VCDMs. As the telecommunications mission substantiates, the identified "most valuable design" is likely to be different by VCDMs having fundamentally differing value ideologies (e.g., discounted cash flow versus utility). While this variance in value is notable, there is also the implicit uncertainty in the value propositions quantified by a single VCDM to consider, only exacerbating the potential variance in the value of a system quantified by several VCDMs. Therefore, for missions having market viability, it is observed that two very different value "schools of thought" lead to two very different recommendations as to most valuable system design. However, for space mission with limited or no market viability, VCDMs not reliant upon monetization of mission attributes prove the more appropriate option.

Ultimately, the case studies provide a rich basis for continued application of VCDMs in an aerospace context, assuming that the attributes for the system of interest are accurately elicited and not biased towards the use of a particular VCDM a priori. One general observation is that systems having credible market viability, or stakeholders who perceive value as profit, are more likely to be appropriately valued using methods relying on monetization. However, in the case in which such market viability diminishes or does not exist, or the stakeholder does not perceive value as profit, then monetization-based VCDMs are likely not appropriate. Given this first observation, within the domain of monetization- and non-monetization-reliant VCDMs, there is a plethora of options, many described herein, and choosing the most appropriate VCDM should be done with informed caution.

The second observation is that when used in conjunction with conceptual design modeling, the application of a particular VCDM may represent a small fraction of the total required effort to value a system, where most of the effort is spent developing the "physics-based" models needed for quantifying the attribute values for the systems under consideration. As motivated by the results from the telecommunications study, it may be desirable to employ the use of more than one VCDM, in order to get multiple perspectives about the "value" of the system. Using multiple VCDMs offers a benefit over assuming a single VCDM and value ideology: it ensures a broader exploration of the system value tradespace while not requiring the investment of much, if any, additional time in modeling the system under consideration. Ultimately, the decision as to the best VCDM, and whether a mixedmethod VCDM approach is best, falls to the stakeholder/user/developer responsible for finding the most valuable system. If they are interested in maximizing the value of their investment in modeling a system, using more than one value ideology or VCDM is likely offer more insights for the effort expended.

\section{Differing Perceptions of Value-Driven Design in the "Real-World": The DARPA System F6 Program}

The expectation of what is "valuable" depends on the system, perspective of relevant stakeholders, and importantly, the comfort of the individual(s) employing a VCDM in making the necessary assumptions. To this end, in the aerospace industry and academia, philosophies about value and thereby value-driven design may have little alliance amongst organizations, and even within them. A recent example of disparity in value perspectives is substantiated through the literature resulting from the DARPA System F6 Program's fractionated spacecraft valuation effort, which has fundamentally focused on justifying (or refuting) the same fractionated spacecraft concept, albeit for different missions in some cases. The DARPA System F6 Program has the long-term objective of demonstrating that fractionated spacecraft are a desirable alternative to monolithic spacecraft in the current spacecraft paradigm. ${ }^{79},{ }^{80}$

One of many facets of the first phase of the program was the development and application of four VCDM tools for providing a risk-adjusted, net value comparison amongst fractionated and monolithic spacecraft designs. The literature from the Phase I of the program regarding the independent development of VCDMs reveals that four major aerospace companies were involved, each developing their own VCDM. These are well-respected companies and thus the following disparity in their interpretations of value is, if anything, an indication of differing philosophies of value-driven design. ${ }^{4,81}$ Three of the companies assessed the "value" of fractionated spacecraft for remote sensing missions, yet one quantified the value of spacecraft using NPV, the other did so using MAUT and then "monetizing" utility, and the other did so using MAUT., ${ }^{4,7,91}$ Furthermore, the remaining company valued a telecommunications and remote sensing mission and did so using both NPV and TOPSIS, providing even more confusion as to the correct valuation method for the same system, collectively supported by the same individuals. ${ }^{66,82,83}$ While this is just one instantiation of the differing perceptions of value in the aerospace industry, it is likely a general observation. Ultimately, the adverse ramifications of these differing value perceptions may be a significant disparity in recommendations as to the most "valuable" design per the VCDM employed, as suggested by an objective comparison of the publicly available versions of all four Phase I VCDM tools. ${ }^{84}$

The valuation assessments of fractionated spacecraft performed through the System F6 Program enumerated trades for these spacecraft that would otherwise be missed through traditional cost and requirement-centric trade study approaches, so they did provide an example of the usefulness of VCDMs, at least in a technical design 
capacity. However, given the disparity in the value quantification by each of the four industry teams in Phase I of the System F6 Program, it strongly suggests the existence of an extreme variance in the "value" of, and hence lack of consensus for, this new spacecraft concept based on the results from Phase I of the program. Thus, from a programmatic standpoint, with such differing perceptions and ensuing quantifications of value from the Phase I, what level of confidence can be placed in selecting one valuation philosophy and ensuing approach for valuing the System F6 Program's planned fractionated spacecraft demonstration mission in the future? ${ }^{85}$ For advocates of fractionated spacecraft, continuation of the spacecraft valuation effort through the System F6 Program in Phase II, wherein only one of the several valuation philosophies, and therefore approaches for valuing spacecraft, was selected, seems an illogical choice given the substantial insights contributed through the respective valuation philosophies adopted by the four aerospace companies from Phase I of the System F6 Program. ${ }^{7,966,81}$

\section{Conclusion}

As discussed in this paper, the goal of "creating value" is usually not controversial in and of itself; however, operationalizing this goal requires making explicit assumptions about a complex and nuanced concept. In order for the valuation engineer to quantify the value of potential systems, it is necessary to align the quantification approach with the expected meaning of the word "value." Economics-based methods provide reasonable approaches for doing so, since economics is about quantifying and predicting exchanges of goods and services (e.g., markets) for stores of value (e.g., money). However, in order to apply economics-based methods, the valuation engineer must identify the type of market in which he finds himself, by recognizing the number of suppliers, demanders, number of exchanges, and uniqueness of the system being designed. The smaller the market and the more unique the system, the more important it will be to explicitly understand the value proposition of both the demander (e.g., customer) and the supplier (e.g., aerospace company) in order to realize a value-creating exchange. As the market grows (e.g., more suppliers and more demanders) this need to understand the preferences of individuals becomes less and less important since what is needed by the supplier is to capture enough demand to make the exchange worthwhile. Commercial space systems tend to fall in the latter category, as commercial markets tend to require the existence of demand in order to justify the development of companies and system products and services. Science space systems tend to fall into the former category, as these systems tend to focus on very unique and specialized missions for which a very small market may exist, if at all. Military space systems tend to fall somewhere in between, where missions are highly specialized, however multiple organizations within the U.S. (or foreign) governments may have similar needs.

Further research is desired in order to develop more prescriptive approaches for determining appropriate valuation methods based on the system type and market. Additionally, little work to date has been done in leveraging insights from behavioral economics into space system valuation (e.g., using CPT). Such research would be very useful in organizing the literature and application of methods in industry and academia on value-driven design, providing an opportunity to focus on moving the state of the practice forward, and clarifying the debate on appropriate methods for valuing system alternatives.

Regardless of one's prior definition of value and use of a favorite VCDM, this paper has highlighted the importance of aligning perspectives of value and methods for valuation in order to pursue value-driven design. The results of the two case studies show that depending on method used for valuation, very different conclusions and insights will be derived, therefore an explicit consideration of the appropriate definition of value is necessary in order to align a chosen method with desired valuation insights.

\section{Appendix}

The single attribute utility (SAU) functions used to derive the multi-attribute utility function and values of the candidate designs for both the telecommunications and deep-space observation mission are given here in turn. Note that all SAU functions are monotonic. Listed in each of the figures hereafter, is the assumed risk preference for the pseudo stakeholder for each mission and their respective attribute preference value (i.e., corner point, $k_{i}$ ); per MAUT, these corner points are not required to equal unity. As demonstrated through Fig. 7 and Fig. 8, the pseudo stakeholder for the telecommunications and deep-space observation mission is assumed generally conservative in their respective decision-making with regard to attaining benefits for a certain cost, with a known risk.

\section{A. Telecommunications Mission}

The following are the single-attribute utility functions for the telecommunications mission. In Fig. 7, HD and $\mathrm{SD}$ are high definition and standard definition channels, respectively. 
AIAA Space 2010

Sept. 2010, Anaheim, CA
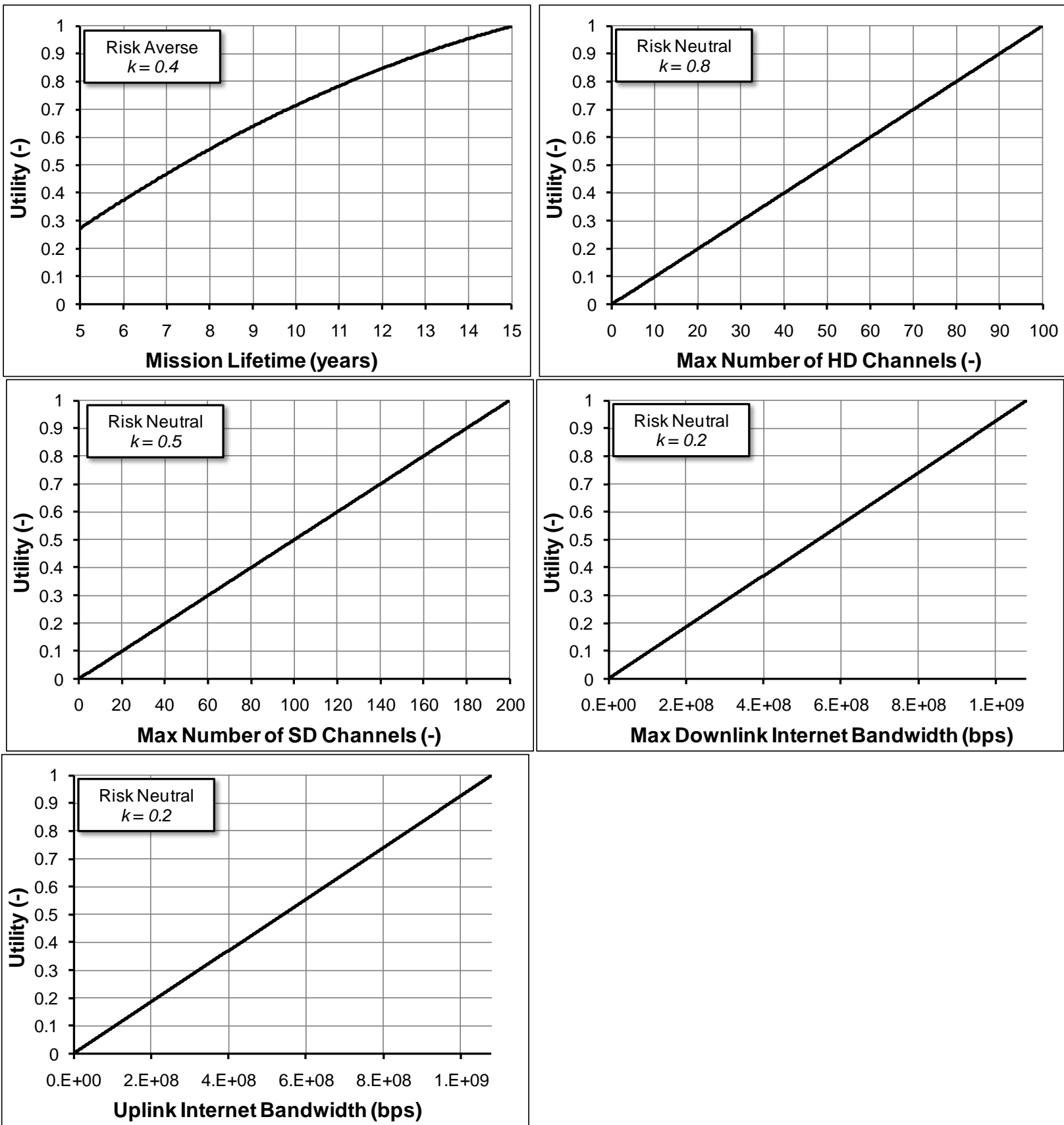

Figure 7. Single attribute utility curves for the telecommunications mission.

\section{B. Deep-Space Observation Mission}

The following are the single-attribute utility functions for deep-space observation mission. In Fig. 8, mas is milli-arcsecond. 
AIAA Space 2010
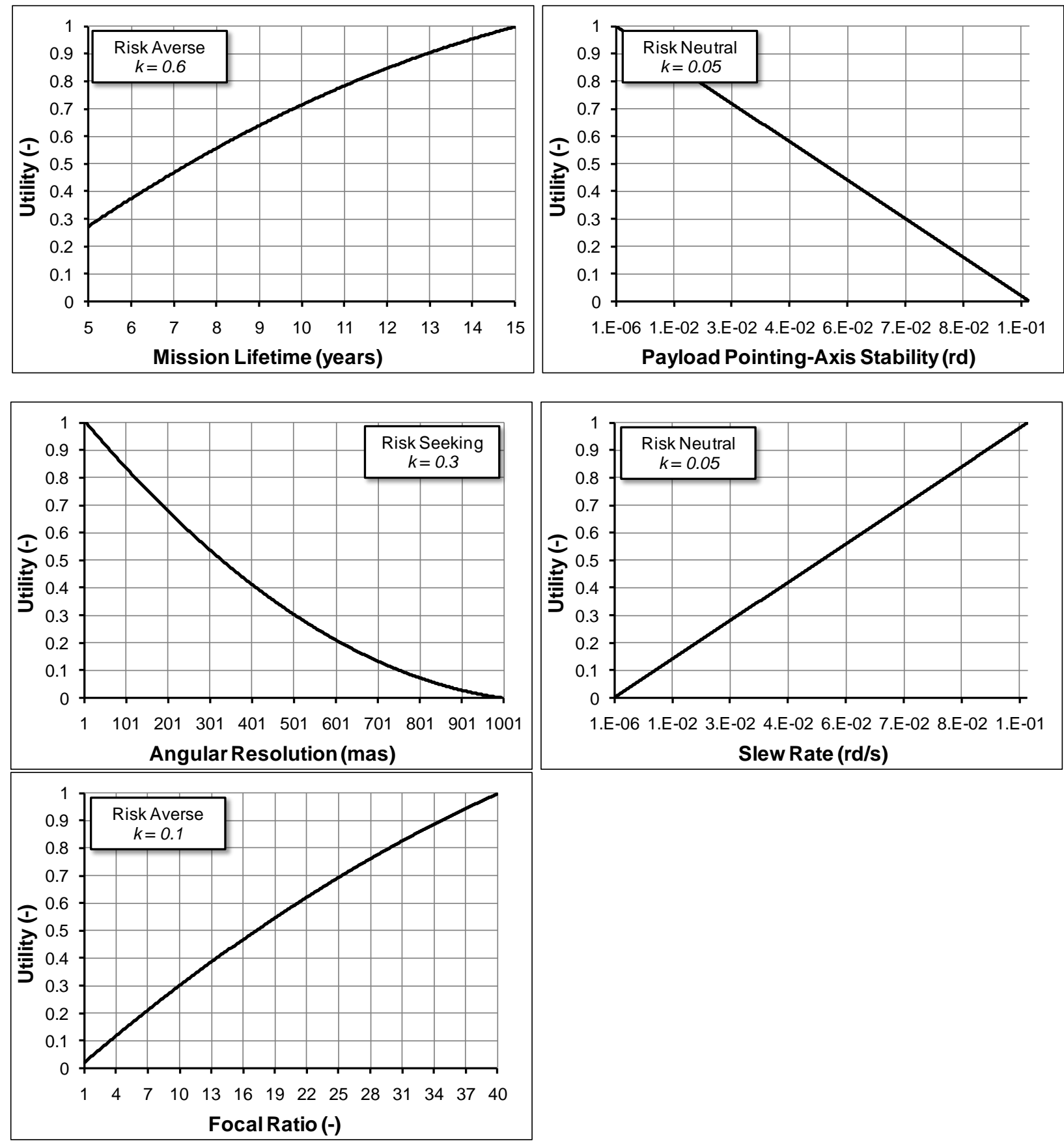

Figure 8. Single attribute utility curves for the deep space observation mission.

\section{Acknowledgements}

Funding for this research was provided in part by the Systems Engineering Advancement Research Initiative (SEAri), a research initiative within the Engineering Systems Division at the Massachusetts Institute of Technology.

\section{References}

\footnotetext{
${ }^{1}$ Brown, O., \& Eremenko, P., "Fractionated Spacecraft as a Testbed for Value-Centric Design (Research)", Defense Advanced Research Projects Agency, 2008.

${ }^{2}$ Brown, O., \& Eremenko, P., “Application of Value-Centric Design to Space Architectures: The Case of Fractionated Spacecraft," AIAA Space 2008, San Diego, CA, 2008.
} 
${ }^{3}$ Brown, O., Eremenko, P., \& Roberts, C., "Cost-Benefit Analysis of a Notional Fractionated SATCOM Architecture," AIAA 24th International Communications Satellite Systems Conference (ICSSC), San Diego, CA, 2006.

${ }^{4}$ Brown, O. C., Eremenko, P., \& Collopy, P. D., "Value-Centric Design Methodologies for Fractionated Spacecraft: Progress Summary from Phase 1 of the DARPA System F6 Program,". AIAA Space 2009. Pasadena, CA, AIAA 2009-6540, 2009.

${ }^{5}$ Collopy, P. D., "Aerospace System Value Models: A Survey and Observations," AIAA Space 2009, Pasadena, CA, AIAA 20096560, 2009.

${ }^{6}$ Diller, N. P.. "Utilizing Multiple Attribute Tradespace Exploration with Concurrent Design for Creating Aerospace Systems Requirements," S.M. Thesis, Aeronautics and Astronautics Dept., Massachusetts Institute of Technology, Cambridge, MA, 2002.

${ }^{7}$ Dragos, M., Chow, J. K., Siddiqi, A., de Weck, O., Alban, S., Dewell, L. D., Howell, A. S., et al., “A Modular, High-Fidelity Tool to Model the Utility of Fractionated Space Systems," AIAA Space 2009, Pasadena, CA, AIAA 2009-6765, 2009.

${ }^{8}$ Mathieu, C., \& Weigel, A., “Assessing the Fractionated Spacecraft Concept,” AIAA Space 2006, San Jose, CA, 2006.

${ }^{9}$ McCormick, D., Barrett, B., \& Clapp-Burnside, M., "Analyzing Fractionated Satellite Architectures using RAFTIMATE - A Boeing Tool for Value-Centric Design,” AIAA Space 2009, Pasadena, CA, AIAA 2009-6767, 2009.

${ }^{10}$ McManus, H., \& Schuman, T. E., "Understanding the Orbital Transfer Vehicle Trade Space," AIAA Space 2003, Long Beach, CA, AIAA 2003-6370, 2003.

${ }^{11}$ Richards, M. G., Ross, A. M., Shah, N. B., \& Hastings, D. E., "Metrics for Evaluating Survivability in Dynamic MultiAttribute Tradespace Exploration," AIAA Space 2008, San Diego, CA, 2008.

${ }^{12}$ Ross, A., "Managing Unarticulated Value: Changeability in Multi-Attribute Tradespace Exploration," Ph.D. Dissertation, Engineering Systems Division Dept., Massachusetts Institute of Technology, Cambridge, MA, 2006.

${ }^{13}$ Saleh, J. H., Jordan, N. C., \& Newman, D. J., "Shifting the Emphasis: From Cost Models to Satellite Utility or Revenue Models The Case for a Value-Centric Mindset in Space System Design," Acta Astronautica, Vol. 61, No. 10, 2007, pp. 889900.

${ }^{14}$ Collopy, P. D., \& Hollingsworth, P., "Value-Driven Design,” AIAA 9th Aviation Technology, Integration, and Operations Conference (ATIO), Hilton Head, SC, AIAA 2009-7099, 2009.

${ }^{15}$ Fischer, K.,. "Value Functions Versus Utility Functions" (Internal), RP0416, Aston Business School, Birmingham, England: Aston University, 2004.

${ }^{16}$ Kahneman, D., \& Tversky, A., "Prospect Theory: An Analysis of Decision Under Risk," Econometrica, Vol. 47, No. 2, 1979, pp. 263-291.

${ }^{17}$ Kahneman, D., \& Tversky, A., eds., Choices, Values, and Frames. 1st ed., Cambridge University Press, New York, 2000.

${ }^{18}$ Keeney, R. L., \& Raiffa, H., Decisions with Multiple Objectives: Preferences and Value Tradeoffs, Cambridge University Press, New York, 1993.

${ }^{19}$ Mishan, E. J., Cost-Benefit Analysis, 5th ed., Routledge, New York, 2007.

${ }^{20}$ Nickel, J., "Using Multi-Attribute Tradespace Exploration for the Architecting and Design of Transportation Systems," S.M. Thesis, Engineering Systems Division Dept., Massachusetts Institute of Technology, Cambridge, MA, 2010.

${ }^{21}$ Ross, A., "Multi-Attribute Tradespace Exploration with Concurrent Design as a Value-Centric Framework for Space System Architecture and Design," S.M. Thesis, Aeronautics and Astronautics Dept. and Technology and Policy Program, Massachusetts Institute of Technology, Cambridge, MA, 2003.

${ }^{22}$ Ross, S. A., Westerfield, R. W., \& Jordan, B. D., Fundamentals of Corporate Finance, 9th ed., McGraw-Hill Irwin, Boston, 2010.

${ }^{23}$ Tversky, A., \& Kahneman, D., “Advances in Prospect Theory: Cumulative Representation of Uncertainty,” Journal of Risk \& Uncertainty, Vol. 5, No. 4, 1992, pp. 297-323.

${ }^{24}$ O'Neill, M. G., "Assessing the Impacts of Fractionation on Pointing-Intensive Spacecraft," S.M. Thesis, Aeronautics and Astronautics Dept., Massachusetts Institute of Technology, Cambridge, MA, 2009.

${ }^{25}$ Osborne, H., Foundations of the Philosophy of Value--An examination of value and value theories, University Press, Cambridge, 1933.

${ }^{26}$ Miriam-Webster Dictionary, http://www.m-w.com, [cited 12 Feb. 2010].

${ }^{27}$ Mill, J.S. and Bentham, J., Utilitarianism and Other Essays, Penguin Classics, London, 1987.

${ }^{28}$ Smith, A., An Inquiry into the Nature and Causes of the Wealth of Nations, Book 1, Chapter IV, section 13, 1776.

${ }^{29}$ Landreth, H. and D.C. Colander, History of Economic Theory, 2nd ed., Houghton Mifflin, Boston, 1989, p. 101.

${ }^{30}$ Ibid., p. 202.

${ }^{31}$ Ibid, p. 277.

32 Ibid.

${ }^{33}$ Calhoun, C., ed., Dictionary of the Social Sciences, Oxford University Press, 2002. Oxford Reference Online, Oxford University Press, Massachusetts Institute of Technology, http://www.oxfordreference.com/, [cited 6 Aug. 2010].

${ }^{34}$ Scott, J., and Marshall, G., A Dictionary of Sociology, Oxford University Press, 2009. Oxford Reference Online, Oxford University Press, Massachusetts Institute of Technology, http://www.oxfordreference.com/, [cited 6 Aug. 2010].

${ }^{35}$ Colman, A.M., ed., A Dictionary of Psychology, Oxford University Press, 2009, Oxford Reference Online, Oxford University Press. Massachusetts Institute of Technology, http://www.oxfordreference.com/, [cited 6 Aug. 2010].

${ }^{36}$ Gabaix, X. and Laibson, D., "Shrouded Attributes, Consumer Myopia, and Information Suppression in Competitive Markets," Quarterly Journal of Economics, Vol. 121, No.2, 2006, pp. 505-540. 
${ }^{37}$ Shleifer, A., Inefficient Markets: An Introduction to Behavioral Finance, Clarendon Lectures in Economics, Oxford University Press, New York, 2000.

${ }^{38}$ Pesendorfer, W., "Behavioral Economics Comes of Age: A Review Essay on Advances in Behavioral Economics," Journal of Economic Literature, Vol. 44, 2006, pp. 712-721.

${ }^{39}$ Fudenberg, D., “Advancing Beyond Advances in Behavioral Economics,” Journal of Economic Literature, Vol. 44, 2006, pp. 694-711.

${ }^{40}$ Brealey, R. A., Myers, S. C., \& Allen, F., Principles of Corporate Finance, 9th ed., .McGraw-Hill Irwin, Boston, 2008.

${ }^{41}$ Keeney, R. L., Value-Focused Thinking: A Path to Creative Decisionmaking, Harvard University Press, Cambridge, MA, 1992.

${ }^{42}$ Arrow, K. J., Social Choice and Individual Values, 2nd ed., Yale University Press, New Haven, CT, 1963.

${ }^{43}$ Gilboa, I., Theory of Decision Under Uncertainty, Cambridge University Press, New York, 2009.

${ }^{44}$ von Neumann, J., \& Morgenstern, O., Theory of Games and Economic Behavior, 3rd ed., Princeton University Press, Princeton, NJ, 1953.

${ }^{45}$ Chattopadhyay, D., Ross, A. M., \& Rhodes, D. H., "Demonstration of System of Systems Multi-Attribute Tradespace Exploration on a Multi-Concept Surveillance Architecture," 7th Annual Conference on Systems Engineering Research 2009 (CSER 2009), Loughborough University, England, 2009.

${ }^{46}$ Viscito, L., Richards, M. G., \& Ross, A. M., “Assessing the Value Proposition for Operationally Responsive Space,” AIAA Space 2008, San Diego, CA, 2008.

${ }^{47}$ Baron, J., Thinking and Deciding, 3rd ed., Cambridge University Press, Cambridge, England, 2000.

48 de Neufville, R., Applied Systems Analysis, 1st ed., McGraw-Hill, New York, 1990.

${ }^{49}$ Ross, A. M., \& Rhodes, D. H., "Using Attribute Classes to Uncover Latent Value during Conceptual Systems Design," 2nd IEEE Systems Conference 2008. Montreal, Canada, 2008.

${ }^{50}$ Ross, A. M., \& Rhodes, D. H., "Using Natural Value-Centric Time Scales for Conceptualizing System Timelines through Epoch-Era Analysis," INCOSE International Symposium 2008, Utrecht, the Netherlands, 2008.

${ }^{51}$ Viscito, L., \& Ross, A. M., "Quantifying Flexibility in Tradespace Exploration: Value Weighted Filtered Outdegree," AIAA Space 2009, Pasadena, CA, 2009.

${ }^{52}$ Nickel, J., Ross, A. M., \& Rhodes, D. H., "Comparison of Project Evaluation Using Cost-Benefit Analysis and Multi-Attribute Tradespace Exploration in the Transportation Domain," 2nd International Symposium on Engineering Systems, Cambridge, MA, 2009.

${ }^{53}$ Fennema, H., \& Wakker, P., "Original and Cumulative Prospect Theory: A Discussion of Empirical Differences," Journal of Behavioral Decision Making, Vol. 10, No. 1, 1997, pp. 53-64.

${ }^{54}$ Gonzalez, R., \& Wu, G., "On the Shape of the Probability Weighting Function," Cognitive Psychology, Vol. 38, No. 1, 1999, pp. 129-166.

${ }^{55}$ Kobberling, V., "Program for Calculating the Cumulative-Prospect-Theory Value of Prospects with at Most Four Outcomes," Retrieved from http://psych.fullerton.edu/mbirnbaum/calculators/cpt_calculator.htm, 2002.

${ }^{56}$ Schmidt, U., \& Zank, H., "Risk Aversion in Cumulative Prospect Theory," Management Science, Vol. 54, No. 1, 2008, pp. 208-216.

${ }^{57}$ Saaty, T. L., "Decision Making — The Analytic Hierarchy and Network Processes (AHP/ANP)," Journal of Systems Science and Systems Engineering, Vol. 13, No. 1, 2004, pp. 1-35.

${ }^{58}$ Wang, Y., \& He, Z., “A TOPSIS Based Robust Optimization Methodology for Multivariable Quality Characteristics,” IEEE International Conference on Service Operations and Logistics and Informatics, Beijing, China, 2008, pp. 2558-2561.

${ }^{59}$ Olson, D., "Comparison of Weights in TOPSIS Models," Mathematical and Computer Modeling, Vol. 40, No. 7-8, 2004, pp. 721-727.

${ }^{60}$ Zanakis, S. H., Solomon, A., Wishart, N., \& Dublish, S., "Multi-Attribute Decision Making: A Simulation Comparison of Select Methods," European Journal of Operational Research, Vol. 107, No. 3, 1998, pp. 507-529.

${ }^{61}$ Yoon, K., "A Reconciliation Among Discrete Compromise Solutions," The Journal of the Operational Research Society, Vol. 38, No. 3, 1987, pp. 277-286.

${ }^{62}$ Chen, Y., Li, K. W., Xu, H., \& Liu, S., “A DEA-TOPSIS Method for Multiple Criteria Decision Analysis in Emergency Management," Journal of Systems Science and Systems Engineering, Vol. 18, No. 4, 2009, pp. 489-507.

${ }^{63}$ Shih, H., Shyur, H., \& Lee, S. E., “An Extension of TOPSIS for Group Decision Making," Mathematical and Computer Modeling, Vol. 45, No. 7-8, 2007, pp. 801-813.

${ }^{64}$ Gass, S. I., "Model World: The Great Debate - MAUT Versus AHP,” Interfaces, Vol. 35, No. 4, 2005, pp. $308-312$.

${ }^{65}$ Saaty, T., Theory and Applications of the Analytic Network Process: Decision Making with Benefits, Opportunities, Costs, and Risks, RWS Publications, Pittsburgh, 2005.

${ }^{66}$ Eichenberg-Bicknell, E., Wisniewski, M. J., Choi, S. W., \& Westley, D. M., "Using a Value-centric Tool Framework to Optimize Lifecycle Cost, Value, and Risk of Spacecraft Architectures," AIAA Space 2009, Pasadena, CA, AIAA 20096766, 2009.

${ }^{67}$ O'Neill, M. G., \& Weigel, A. L., “Assessing the Impacts of Fractionation on Pointing-Intensive Spacecraft,” AIAA Space 2009, Pasadena, CA, AIAA-2009-6801, 2009.

${ }^{68}$ O'Neill, M. G., \& Weigel, A. L., "Assessing Fractionated Spacecraft Value Propositions for Earth Imaging Space Missions,” Journal of Spacecraft and Rockets, accepted for publication 7 Jun. 2010. 
AIAA Space 2010

${ }^{69}$ DirecTV, Inc., "DirecTV Packages,” http://www.directv.com/DTVAPP/content/packages/overview [cited 5 July 2010].

${ }^{70}$ Verizon Wireless, "Verizon Wireless. Mobile Broadband Plans," Retrieved from http://www.verizonwireless.com/b2c/mobilebroadband/?page=plans\&lid=//global//plans $/ /$ mobile+broadband [cited $5 \mathrm{July}$ 2010].

${ }^{71}$ Larson, W. J., \& Wertz, J. R., Space Mission Analysis and Design (SMAD), 3rd ed., Microcosm Press, New York, 1999.

72 DirecTV, Inc., "DirecTV. Investor Relations.” Retrieved from http://dtv.client.shareholder.com/ [cited 19 July 2010 ].

${ }^{73}$ Baldesarra, M., "A Decision-Making Framework to Determine the Value of On-Orbit Servicing Compared to Replacement of Space Telescopes," S.M. Thesis, Aeronautics and Astronautics Dept., Massachusetts Institute of Technology, Cambridge, MA, 2007.

${ }^{74}$ NASA. 2008 NASA Cost Estimating Handbook, National Aeronautics and Space Administration, Hanover, MD, 2008.

${ }^{75}$ Harwood, W., "Final servicing Mission Begins to Extend Hubble's Life," Spaceflight Now, Retrieved from http://spaceflightnow.com/shuttle/sts125/090511launch/, 11 May 2009, [cited 16 June 2010].

${ }^{76}$ Okolski, G., "A Brief History of the Hubble Space Telescope," National Aeronautics and Space Administration History Division. Retrieved from http://history.nasa.gov/hubble/index.html, 18 Apr 2008, [cited 16 June 2010].

${ }^{77}$ Lagerstrom, J., "Measuring the Impact of the Hubble Space Telescope: Open Data as a Catalyst for Science," World Library and Information Congress: 76th IFLA General Conference and Assembly, Gothenburg, Sweden, 2010.

${ }^{78}$ Nilchiani, R., Hastings, D. E., \& Joppin, C., "Calculations of Flexibility in Space Systems," 2004 Engineering Systems Division Symposium, Cambridge, MA, 2004.

${ }^{79}$ Defense Advanced Research Projects Agency, Tactical Technology Office, "DARPA Awards Contracts for Fractionated Spacecraft Program," Retrieved from www.darpa.mil/news/2008/F6.pdf, 26 Feb 2008, [cited 11 Jun 2008].

${ }^{80}$ Defense Advanced Research Projects Agency, Tactical Technology Office, "DARPA Awards Contract for Detailed Design of Fractionated Spacecraft Program," Retrieved from http://www.darpa.mil/news/2009/F6 NewsRelease December2009.pdf, 4 Dec. 2009, [cited 10 Feb 2010].

${ }^{81}$ O'Neill, M. G., Yue, H., Nag, S., Grogan, P., \& de Weck, O., “Comparing and Optimizing the DARPA System F6 Program Value-Centric Design Methodologies," AIAA Space 2010, Anaheim, CA, 2010.

${ }^{82}$ Lafleur, J. M., \& Saleh, J. H., "GT-FAST: A Point Design Tool for Rapid Fractionated Spacecraft Sizing and Synthesis," AIAA Space 2009, Pasadena, CA, AIAA 2009-6563, 2009.

${ }^{83}$ Lafleur, J. M., \& Saleh, J. H., "Exploring the F6 Fractionated Spacecraft Trade Space with GT-FAST," AIAA Space 2009, Pasadena, CA, AIAA 2009-6802, 2009.

${ }^{84}$ Nag, S., Yue, H., O'Neill, M. G., \& Grogan, P., "System F6 Phase 1 Value-Centric Design Methodology Benchmarking and Best Practices," Technical Memorandum, Massachusetts Institute of Technology, Cambridge, MA, 2010.

${ }^{85}$ Defense Advanced Research Projects Agency, Tactical Technology Office, "System F6 Informational," Retrieved from http://www.darpa.mil/tto/programs/systemf6/, 2010, [cited $10 \mathrm{Feb} 2010$ ]. 